\title{
The Impact of Economic Growth and Air Pollution on Public Health in 31 Chinese Cities
}

\author{
Ying $\mathrm{Li}^{1}$, Yung-ho Chiu ${ }^{2, *}$ and Tai-Yu Lin ${ }^{2}$ (I) \\ 1 Business School, Sichuan University, Wangjiang Road No. 29, Chengdu 610064, China; liyinggs@scu.edu.cn \\ 2 Department of Economics, Soochow University, 56, Kueiyang St., Sec. 1, Taipei 10048, Taiwan; \\ eickyla@gmail.com \\ * Correspondence: echiu@scu.edu.tw; Tel.: +886-2-23111531 (ext. 5201); Fax: +886-2-27976015
}

Received: 4 December 2018; Accepted: 24 January 2019; Published: 30 January 2019

check for updates

\begin{abstract}
The rapid economic growth of China in the last twenty years has caused a commensurate rise in atmospheric pollution which has had an impact on both the environment and public health. Since $2013, \mathrm{SO}_{2}, \mathrm{CO}_{2}$ and nitrogen oxide levels have reached a level that may cause climate change and have adverse effects on the health of the local residents. Past environmental efficiency analyses have rarely examined economic development, air pollution and health as interacting systems; therefore, this study used a new two-stage DEA model, the Modified Undesirable EBM Two Stage DEA (Epsilon-Based Measure) to explore the environmental, economic and health efficiencies in thirty-one major cities in China. The results were as follows: while all cities needed to improve their GDP, the environmental efficiencies were continuing to rise in most cities. The health efficiency index indicated that disease efficiency had increased in most cities but declined in one third; therefore, it is necessary to strengthen treatment. The respiratory disease treatment efficiency in most cities was rising, and the room for improvement had significantly reduced. There were improvements in the mortality rate in 15 cities; however, the mortality rate treatment efficiency declined in 11 cities.
\end{abstract}

Keywords: environmental efficiency; Epsilon-Based Measure; health expenditure; network SBM

\section{Introduction}

To accompany its growing economy over the past few decades, China has consumed large amounts of coal and oil, which has resulted in a significant drop in air quality in many cities and has had a significant impact on the environment and public health. The World Meteorological Organization (WMO) reported that the current $\mathrm{CO}_{2}$ concentrations in the Earth's atmosphere were now $145 \%$ of the level before industrialization [1]. This rapid rise in $\mathrm{CO}_{2}$ has resulted in climate change effects such as the rapid loss in sea ice through melting, which has begun to endanger coastal cities and affect river flows, which in turn have affected production activities.

Many countries are now seeking to limit their carbon emissions, and China is also aiming to have "ambient air quality standards" [2] by 2040 for half the population. Because air pollution is already a major threat to public health and the impact of $\mathrm{SO}_{2}, \mathrm{NO}_{2}, \mathrm{PM}_{2.5}$ and $\mathrm{CO}_{2}$ on respiratory and cardiovascular diseases especially in children can be quite severe.

Environmental pollution research is generally linked to the assessment of the economy and energy efficiency. Zhou et al. [3] used non-oriented DEA to examine the carbon emission environmental performance in eight regions-OECD member countries, the Middle East, countries of the former Soviet Union, the non-OECD European countries, Asian countries outside China, China, Latin America, and Africa-by evaluating the non-increasing return to scale and variable return to scale efficiencies in each region. Sueyoshi and Mika [4] used the original non-radial DEA model to study the effect of the US Clean Air Act (CAA) on acid-induced gases $\left(\mathrm{NO}_{\mathrm{x}}\right)$ and found that under the CAA regulations, 
acid rain was effective in controlling the $\mathrm{SO}_{2}$ and $\mathrm{NO}_{x}$ emissions from U.S. coal-fired power plants. Shi et al. [5] used a Radial DEA model to analyze China's energy efficiency, finding that the energy efficiency in eastern China was the best. Choi et al. [6] adopted a slack-based DEA to analyze China's energy efficiency and found that China's carbon dioxide efficiency was poor. Zhang and Choi [7] used an SBM-DEA to study the environmental efficiencies in various provinces in China and found that most provinces had low energy efficiencies. Sueyoshi and Mika [8] used DEA and the Malmquist index to examine the frontier changes between multiple periods, and studied the relationship between fuel mixtures, electricity, and carbon dioxide in 10 industrial countries, finding that the nuclear power generation in France, the water resources in The Netherlands, and renewable energy were important for the sustainable development of the society. Wu et al. [9] used the Radial DEA and Malmquist methods to explore the energy efficiency of China's regions and found that the average energy efficiency in eastern and central China was higher. Chang [10] used Radial DEA to explore EU energy efficiency and found that the increase in energy intensity was related to a decrease in the energy intensity need for improvements. Wang and Wei [11] used a DDF model to analyze China's energy efficiency and found that the energy efficiency was affected by the significant growth in carbon dioxide emissions. Pang et al. [12] used SBM DEA to analyze efficiencies in 87 countries and found that European countries were more efficient in emissions reduction and energy efficiency. Guo et al. [13] employed dynamic DEA models to assess the intertemporal efficiencies in OECD countries, and found that most countries had improved efficiencies. Georgiev et al. [14] evaluated the Environmental Kuznets Curve (EKC) for six air pollutants, namely $\mathrm{SO}_{x}, \mathrm{NO}_{x}, \mathrm{CO}$, VOC $\mathrm{CO}_{2}$, and GHG, in OECD countries. Some air pollutant emissions did not follow the shape of EKC, but $\mathrm{SO}_{X}$ emissions show a U-shaped Environmental Kuznets Curve. He et al. [15] presented an assessment of the marginal abatement cost of the industrial sector in China. Li et al. [16] measured the damage caused by $\mathrm{PM}_{10}$ and $\mathrm{SO}_{2}$ in 74 cities in China in 2015. The above two air pollutants could cause economic losses related to health issues equal to 1.63 and $2.32 \%$ of the GDP. Wang et al. [17] estimated the relation between $\mathrm{CO}_{2}$ emissions and economic growth. The results showed that urbanisation level has a more significant effect on carbon emission than Gross Domestic Product per capita and energy structure. Xie et al. [18] used a computable general equilibrium (CGE) model and the latest non-linear exposure-response functions to assess the impact energy on China's national and provincial economies, and found that in provinces with high concentrations of energy, the effect on health has had a significant impact on the economy. It was estimated that China's GDP losses would be $2 \%$ by 2030 , and the medical expenses would be around US $\$ 25.2$ billion.

Environmental pollution and health have had two main research directions_an assessment of the impact of environmental air pollutant exposure on health, and the impact of environmental air pollution on the health of children and the elderly. Liu et al. [19] investigated the effect of socioeconomic variables (education, income, life satisfaction, etc.) and air pollution on health in different regions (East, Central, West) of China in 2015. The results show that good air quality in spring and summer has a positive effect on health, but the bad air quality in autumn and winter has a negative effect on health. Zanoni et al. [20] investigated the effect of civilian activities on Indoor Air Quality (IAQ) in Italy in 2013. The results show that church services, public transportation, and $A / C$ in cars do have an effect on IAQ. Kelly and Fussell [21] concluded that particulate matter (PM) has not only had a major impact on health over the past 10 years, but was also associated with many diseases, with the $\mathrm{PM}_{2.5}$ concentrations having a particularly significant impact on health. Fischer et al. [22] explored the relationship between long-term exposure to air pollution, urban living, and societal health using the Land Use Regression (LUR) method and found that: (1) For every $10 \mu \mathrm{g} / \mathrm{m}^{3}$ increase, $\mathrm{PM}_{10}$ and $\mathrm{NO}_{2}$ were significantly associated with non-accidental mortality; (2) $\mathrm{PM}_{10}$ was related to circulatory system mortality, but $\mathrm{NO}_{2}$ was not; and (3) Long-term exposure to $\mathrm{PM}_{10}$ and $\mathrm{NO}_{2}$ was associated with (non-accidental causes) mortality in The Netherlands for people over 30. Khafaie et al. [23] focused on the links between air pollution and health and reviewed the different estimation methods, finding that the quality of the exposure measurements was a key determinant in epidemiological studies and that 
available exposure data collection methods were often related to the design determinants. Khafaie et al. also conducted a historical review of air pollution research [24], providing a comprehensive analysis of the health effects of harsh air quality, evaluating the rational biological mechanisms of the impact of air pollution, and identifying specific air pollutants.

Tainio et al. [25] analyzed the relationship between different levels of exercise and air pollution related mortality, and found that in an area that has a $\mathrm{PM}_{2.5}$ concentration of $100 \mu \mathrm{g} / \mathrm{m}^{3}$, the benefit from riding for one and a half hours a day or walking for more than $10 \mathrm{~h}$ a day was less than the damage from the air pollution, and in areas with a lower $\mathrm{PM}_{2.5}$ concentration, the benefit of cycling for $3 \mathrm{~h}$ and a half rather than staying home was greater than the damage from the air pollution. Jose et al. [26] measured the effect of climate on citizen's health in two areas (Kensington and Chelsea) in London. The results showed that MICROSYS-CFD model can be benefit for urban atmosphere assessment and environmental policy design. Torretta et al. [27] discussed the pollution caused by particulate matter in Italy and provide policy suggestion. Schiavon et al. [28] assessed the effect of $\mathrm{NO}_{\mathrm{x}}$ on health in Italy and provide governance recommendation to avoid health risk. Schiavon et al. [29] simulated the $\mathrm{NO}_{\mathrm{x}}$ emissions of road traffic. The results show that high emission concentrations can affect the human body.

Cohen et al. [30] explored the spatial and temporal trends in mortality and diseases caused by air pollution at global, regional, and national levels. Through satellite estimation, a chemical transmission model, and ground level measurements, it was found that environmental $\mathrm{PM}_{2.5}$ ranked fifth among all mortality risk factors, with exposure to $\mathrm{PM}_{2.5}$ causing 42 million deaths, which was $7.6 \%$ of the total global mortality, and 1031 million disability-adjusted life years (DALYs). Johansson [31] used transport models to select commuter preference data for Stockholm County to analyze the effect of $\mathrm{NO}_{x}$ and black carbon $(\mathrm{BC})$ on the mortality rate, and showed that a $7 \%$ decrease in the average exposure to nitrogen oxides and black carbon (BC) would reduce the relative risk of mortality by $8 \%$. Newell et al. [32] explored the health effects of exposure to air pollutants, and found that a $10 \mu \mathrm{g} / \mathrm{m}^{3}$ increase in $\mathrm{PM}_{2.5}$ increased the risk of cardiovascular mortality by $0.47 \%$ and respiratory mortality by $0.57 \%$ (0.28-0.86), and a $10 \mu \mathrm{g} / \mathrm{m}^{3}$ increase in $\mathrm{PM}_{10}$ increased the risk of cardiovascular mortality by $0.27 \%$ (0.11-0.44) and respiratory mortality by $0.56 \%(0.24-0.87)$. Kinney [33] reviewed research on the effects of climate change on air quality and human health and found that climate and weather had a large impact on the spatial and temporal distribution of air pollution concentrations; for example, at higher ambient temperatures, ozone and $\mathrm{PM}_{2.5}$ emissions increased, and ozone formation was faster in high sunlight and high temperatures. Lua et al. [34] measure the effect of the $\mathrm{PM}_{2.5}$ on health in China from 2001 to 2017. The $\mathrm{PM}_{2.5}$ is related to the mortality rate in urban. The reduction of the $\mathrm{PM}_{2.5}$ can brings the benefit about $\$ 193,800$ in 2017.

Zigler [35] used causal inference methods and a spatially hierarchical regression model to investigate the impact of environmental fine particulate matter in 2005 (which did not meet the 1997 national environmental air quality standard) on environmental $\mathrm{PM}_{2.5}$, and found that at all research sites, any reductions in environmental $\mathrm{PM}_{2.5}$ and health insurance could not be attributed to the substandard conditions in eastern United States. A hierarchical analysis showed that if $\mathrm{PM}_{2.5}$ reduced to levels beyond the regional measures, mortality, chronic obstructive pulmonary disease, heart failure, ischemic heart disease, and respiratory infections would be significantly reduced.

Some research has discussed the impact of environmental air pollution on the health of children and the elderly. Frischer et al. [36] used regression analysis to estimate the links between air pollutants and lung function in 1,150 children in two Austrian counties from 1994-1996, and found that ozone had a significant negative effect on the first second of forced expiration $\left(\mathrm{FEV}_{1}\right)$, forced vital capacity (FVC), and maximal expiratory flow at $50 \%$ of the vital flow capacity $\left(\mathrm{MEF}_{50}\right)$. However, $\mathrm{PM}_{10}, \mathrm{SO}_{2}, \mathrm{NO}_{2}$ were not found to have a significant negative effect on lung function. Ye et al. [37] used generalized linear models (GLMs) to research the effects of exposure to higher daily maximum temperatures and concentrations of air pollutants in Tokyo during the summer months of July and August from 1980 to 1995 on cardiovascular and respiratory diseases in people over 65 years old, and found that $\mathrm{NO}_{2}$ 
had a significant effect on angina, cardiac insufficiency, myocardial infarction, and acute bronchitis, and $\mathrm{PM}_{10}$ had a significant effect on asthma, chronic bronchitis, and pneumonia.

Lee et al. [38] used a generalized additive model (GAM) time series analysis to explore the effect of multiple air pollutants; sulfur dioxide $\left(\mathrm{SO}_{2}\right)$, nitrogen dioxide $\left(\mathrm{NO}_{2}\right)$, ozone $\left(\mathrm{O}_{3}\right)$, carbon monoxide (CO) and airborne particles less than or equal to $10 \mu \mathrm{g} / \mathrm{m}^{3}$ in aerodynamic diameter $\left(\mathrm{PM}_{10}\right)$; on the health of children under 15 years old in Seoul from 1997 to 1999, and found that nitrogen dioxide and ozone were the main factors for childhood asthma. Gauderman et al. [39] estimated the relationship between air pollution and lung function using linear regression in children in the fourth, seventh, and tenth grades in southern California in 1993, and found that $\mathrm{PM}_{2.5}, \mathrm{PM}_{2.5-10}, \mathrm{PM}_{10}$ and $\mathrm{NO}_{2}$ had significantly negative effects on the first second of forced expiration (FEV), forced vital capacity (FVC), maximal mid-expiratory flow (MMEF), and improved forced expiratory flow at $75 \%$ of vital capacity $\left(\mathrm{FEF}_{75}\right)$; however, ozone was not found to have a significant negative effect on lung function.

Chen et al. [40] used generalized linear models (GLMs) to explore the association between particulate matter (PM) and hospitalization for chronic obstructive pulmonary disease (COPD) and found that $\mathrm{PM}_{2.5}, \mathrm{PM}_{2.5-10}$ and $\mathrm{PM}_{10}$ all had significant effects.

Penard-Morand et al. [41] used a cross-sectional study of 6672 children from 9-11 years old at 108 randomly selected schools in France to research the impact of air pollution on asthma and allergies, and found that lifetime asthma and lifetime allergic rhinitis were positively related to an increased exposure to $\mathrm{SO}_{2}, \mathrm{PM}_{10}$ and $\mathrm{O}_{3}$; however, no consistent positive association was found for $\mathrm{NO}_{2}$; and that long-term exposure to background ambient air pollution increased the prevalence of respiratory and atopic problems in children. Barnet et al. [42] conducted a meta- analysis on children in two cities in New Zealand and five cities in Australia from 1998-2001 and found an association between outdoor pollution and hospital admissions, with the results showing that the outdoor pollutants $\mathrm{PM}_{2.5}, \mathrm{PM}_{10}$, $\mathrm{SO}_{2}, \mathrm{NO}_{2}$ and $\mathrm{O}_{3}$ had significant effects on pneumonia and acute bronchitis for children less than 1 and 1-4 years old, on respiratory problems in all three groups, and on asthma in 5-14 year old. $\mathrm{SO}_{2}$ has also been found to have an effect on pregnant women by shortening pregnancies, and causing premature births and low birth weights (Choe et al., [43]). A study of long-term exposure to $\mathrm{PM}_{2.5}$ and mortality in the elderly found (Wang and Shi [44]) that for every $1 \mu \mathrm{g} / \mathrm{m}^{3}$ increase in atmospheric $\mathrm{PM}_{2.5}$, the hazard ratio for mortality (HR) was 1.021 (95\% CI: 1.019 to 1.022 ).

However, there have been few studies that have considered the interactions between economic growth, environmental pollution, and community health. Most environmental pollution and economic analysis research has employed radial (such as Cooper, Charanes and Rhodes Model or Banker, Chames and Cooper Model) or non-radial (Slack Based Model) Data Envelopment Analyses (DEA) and Distance Function Models (DDFC Directional). However, the radial DEA model ignores non-radial slacks and non-radial DEA models ignore characteristics of the same proportion. As traditional environmental pollution and economic research have tended to employ one-stage DEA as the main methodology, health issues have generally been ignored. Therefore, to resolve the issues associated with radial and non-radial bias, this research proposes a Modified Undesirable EBM Two stage model.

The main contribution of this paper is that the economic, environmental, and health efficiencies are jointly analyzed, which avoids under- or overestimation. Data from 31 Chinese cities from 2013-2016 were examined in two stages: a production stage and a health stage. In the production stage, labor, fixed assets, and energy consumption were the input indicators Gross Domestic Product (GDP) as output indicator, linkage and health stage variable are $\mathrm{CO}_{2}$ and Air Quality Index (AQI). In health stage the health expenditure is input indicator; the output indicators are birth rate, respiratory system and mortality rate.

The remainder of this paper is organized as follows: Section 2 presents the Materials and methods; Section 3 is the Results and Discussion; Section 4 is Conclusions. 


\section{Materials and Methods}

Data envelopment analysis (DEA) uses linear programming techniques to assess the relative efficiency of decision making units (DMU) based on a Pareto optimal solution concept. Charnes et al. [45] developed the data envelopment analysis CCR DEA model based on the "frontier" concept by Farrell [46]). Banker et al. [47] then extended the assumption for the returns to scale and proposed the BCC model. As both CCR and BCC are Radial DEA models that ignore non-radial slacks when evaluating efficiency values, Tone proposed the Slacks-Based Measure (SBM) in 2001 [48] using the slack variable as a basis for measurement that considered the slacks between the inputs and outputs to provide an SBM efficiency that employed a non-radial estimation and single scalar method, with the radial DEA model being represented by the CCR and BCC and the non-radial DEA model being represented by the SBM. However, both models had shortcomings as the radial DEA model ignored the non-radial slacks when evaluating the efficiency value, and the non-radial DEA (such as SBM) failed to consider the radial characteristics when evaluating the efficiency value slacks, and therefore characteristics with the same radial proportion were ignored. Therefore, to solve these shortcomings, Tone and Tsutsui [49] proposed the Epsilon-Based Measure (EBM) DEA model, that included investment and output orientations and a non-orientation.

When evaluating efficiency, traditional DEA models convert the efficiency between the two variables through the input and output, with the conversion process being a "black box". Fare et al. [50] then proposed Network Data Envelopment Analysis (Network DEA), which considered a production process composed of many sub-production technologies, which were regarded as sub-decision units (Sub-DMU), using traditional CCR and BCC models to determine the optimal solution. Zhu [51] described the value chain process as a "black box" and believed that it contained some sub-processes that constituted the value chain system. When estimating system efficiency, each sub-process also requires an efficiency evaluation. Chen and Zhu [52], Hwang and Kao [53], Kao and Hwang [54], and Kao [55] divided the entire business process into sub-processes that linked each stage with intermediate outputs. The efficiency of each stage was then calculated separately under different conditions, and which sub-process led to system efficiency losses were analyzed. Tone and Tsutsui [56] proposed a weighted slack-based measures network data envelopment analysis model (weighted slack-based measures) in which the links between the various departments of a decision-making unit were used as the basis for the Network DEA model analysis, and each department was seen as a Sub-DMU, after which the SBM mode was used to find the optimal solution.

Although the EBM DEA model overcame the shortcomings of the radial and the non-radial DEA models, it is still unable to solve the issues associated with two-stage undesirable output, and while Network DEA models can solve the multi-stage problems, they fail to solve the radial and non-radial problems. Therefore, this paper proposes a modified EBM Two-stage DEA model based on Tone and Tsutsui's [49] Two-stage and modified EBM DEA model.

\subsection{EBM DEA, Network SBM DEA and Modified Undesirable EBM Two Stage DEA Framework}

The Non-oriented EBM DEA description in Tone and Tsutsui [49] is as follows:

There are $n D M U s$, where $D M U_{j}=\left(D M U_{1}, D M U_{2}, \ldots, D M U_{k}, \ldots, D M U_{n}\right)$, there are $m$ types of input $X_{j}=\left(X_{1 j}, X_{2 j}, \ldots, X_{m j}\right)$, and there are $s$ outputs, where $Y_{j}=\left(Y_{1 j}, Y_{2 j}, \ldots, Y_{s j}\right)$; the efficiency of the DMU unit is therefore [49]

$$
\theta^{*}=\min _{0, \eta, \lambda, s^{-}, s^{+}} \frac{\theta-\varepsilon_{x} \sum_{i=1}^{m} \frac{w_{i}^{-} s_{i}^{-}}{x_{i 0}}}{\eta+\varepsilon_{y} \sum_{i=1}^{s} \frac{w_{i}^{+} s_{i}^{+}}{y_{i 0}}}
$$

Subject to:

$$
\theta X_{0}-X_{\lambda}-S^{-}=0, \eta Y_{0}-Y_{\lambda}+S^{+}=0, \lambda_{1}+\lambda_{2}+\ldots+\lambda_{n}=1 \lambda \geq 0, S^{-} \geq 0, \quad S^{+} \geq 0
$$


where $Y$ : DMU output, $X$ : DMU input, $S^{-}$: slack variable, $S^{+}$: surplus variable, $W^{-}$: weight of input $i, \sum W_{i}^{-}=1\left(\forall_{i} W_{i}^{-} \geq 0\right), W^{+}$: weight of output $S, \sum W_{i}^{+}=1\left(\forall_{i} W_{i}^{+} \geq 0\right), \varepsilon_{x}$ : set of radial $\theta$ and non-radial slacks, $\varepsilon_{y}$ : set of radial $\eta$ and non-radial slacks.

For DMU0, when $\theta^{*}=1$, EBM is considered the most non-oriented efficient. If the DMU is inefficient, the following adjustments are needed [49]:

$$
\begin{gathered}
X_{0}^{*}=X \lambda^{*}=\theta^{*} X_{0}-S^{-*} \\
Y_{0}^{*}=Y \lambda^{*}=\eta^{*} y_{0}+S^{+}
\end{gathered}
$$

\subsection{Non-Oriented Network SBM DEA}

In 2009, Tone and Tsutsui proposed a weighted slack-based measures (DEM) model to measure the overall efficiency of decision-making units and the efficiency of each department and included an SBM mode non-radial measure when the input and output items could not be adjusted in equal proportions. The network DEA model based on the weighted SBM is introduced in the following: Considering both the input and output slacks, Equation (3) represents non-oriented efficiency [49]:

$$
\begin{gathered}
\operatorname{Min} \rho_{0}^{*}=\frac{\sum_{k=1}^{K} w^{k}\left[1-\frac{1}{m_{k}}\left[\sum_{i=1}^{m_{k}} s_{i 0}^{k-} / X_{i 0}^{k}\right]\right]}{\sum_{k=1}^{K} w^{k}\left[1+\frac{1}{r_{k}}\left[\sum_{r=1}^{m_{k}} s_{i 0}^{k+} / Y_{r 0}^{k}\right]\right]} \\
\sum_{k=1}^{K} w^{k}=1, \forall k \\
w^{k} \geq 0, \forall k
\end{gathered}
$$

According to Equation (4), the definition for the non-oriented department efficiency is as follows [49]:

$$
\rho_{k}=\frac{1-\frac{1}{m_{k}}\left[\sum_{i=1}^{m_{k}} s_{i 0}^{k-*} / X_{i 0}^{k}\right]}{1+\frac{1}{r_{k}}\left[\sum s_{r 0}^{k+*} / Y_{r 0}^{k}\right]}, k=1,2, \ldots, K
$$

where $s_{i 0}^{k-*}$ and $s_{r 0}^{k+*}$ are the optimal input and output slacks, $\rho_{k}^{*}=1$ indicates that the $k$-th department of $D M U_{o}$ is non-oriented efficient, and indicates that $D M U_{o}$ has non-oriented overall efficiency.

\subsection{The Empirical Model for this Study: Modified Undesirable EBM Two Stage DEA Model}

By combining the modified EBM DEA with a Two-stage DEA and undesirable factors, this paper proposes a modified EBM Two stage DEA model to evaluate the energy efficiency of 31 cities in China, which avoids the efficiency and need for improvement being under or overestimated.

The modified undesirable EBM Two stage DEA is as follows:

The number of DMUs is $n$, the number of divisions is $k$, where $D M U_{j}=\left(D M U_{1}, D M U_{2}, \ldots, D M U_{k}\right.$, $\left.\ldots, D M U_{n}\right)$. there are $m$ input types $X_{j}=\left(X_{1 j}, X_{2 j}, \ldots, X_{m j}\right)$, and there are $s$ outputs where $Y_{j}=\left(Y_{1 j}, Y_{2 j}\right.$, $\left.\ldots, Y_{s j}\right)$, therefore, the efficiency of the DMU unit is:

$$
\theta^{*}=\min _{0 \eta, \lambda, s^{-}, s^{+} g, s^{-b}} \frac{\sum_{k=1}^{K} W^{k}\left[\theta_{k}-\varepsilon_{x k} \sum_{i=1}^{m_{k}} \frac{w_{i}^{-k} s_{i}^{-k}}{x_{i 0}}\right]}{\sum_{k=1}^{K} W^{k}\left[\eta_{k}+\varepsilon_{y k}\left[\sum_{i=1}^{S_{1 k}} \frac{w_{i}^{+S_{1 k}} s_{i}^{+g k}}{y_{i 0}}+\sum_{i=1}^{S_{2 k}} \frac{w_{i}^{-S_{2 k}} s_{i}^{-b k}}{y_{i 0}}\right]\right]}
$$


Subject to:

$$
\begin{gathered}
\theta_{k} X_{0}^{k}-X_{\lambda}^{k}-S^{-k}=0, \\
\eta_{k} Y_{0}^{k}-Y_{\lambda}^{+g k}+S^{+g k}=0 \\
\eta_{k} Y_{0}^{k}-Y_{\lambda}^{-b k}+S^{-b k}=0 \\
Z^{(k, h)}=Z^{(k, h)} \lambda^{h}(\forall(\mathrm{k}, \mathrm{h})) \\
\lambda_{1}^{k}+\lambda_{2}^{k}+\ldots+\lambda_{n}^{k}=1 \\
\lambda^{k} \geq 0, S^{-k} \geq 0, S^{+g k} \geq 0, S^{-b k} \geq 0, \theta_{k} \leq 1, \eta_{k} \geq 1
\end{gathered}
$$

where $Y$ : DMU output, $X$ : DMU input, $S^{-k}$ : slack variable, $S^{+g k}$ : surplus variable, $S^{-b k}$ : surplus variable, $W^{-k}$ : weight of input I, $\sum W_{i}^{-}=1\left(\forall_{i} W_{i}^{-} \geq 0\right), W^{+k}$ : weight of output $S, \sum W_{i}^{+S_{1 k}}+$ $\sum W_{i}^{-S_{2 k}}=1\left(\forall_{i} W_{i}^{+k} \geq 0\right), \varepsilon_{x k}$ : set of radial $\theta$ and non-radial slacks, $\varepsilon_{y k}$ : set of radial $\eta$ and non-radial slacks, and $(k, h)$ : the link from Division $k$ to Division $h$.

The efficiency score for Division $k$ is given by:

$$
\rho_{k}=\frac{\theta_{k}-\varepsilon_{x k} \sum_{i=1}^{m_{k}} \frac{w_{i}^{-k} s_{i}^{-k}}{x_{i 0}}}{\eta_{k}+\varepsilon_{y k}\left[\sum_{i=1}^{S_{1 k}} \frac{w_{i}^{+S_{1 k} s_{i}^{+g k}}}{y_{i 0}^{+g k}}+\sum_{i=1}^{S_{2 k}} \frac{w_{i}^{-S_{2 k}} s_{i}^{-b k}}{y_{i 0}}\right]}
$$

when $\rho_{k}^{*}=1$, the $k$ is the department, $D M U_{o}$ is non-oriented efficient and when $\rho_{0}^{*}=1, D M U_{o}$ has non-oriented overall efficiency. The DMU and division overall efficiency is assessed as the non-oriented unit the efficiency value and the measurement unit selected by the input, output, and the intermediaries are independent of each other.

If an inefficient decision-making unit needs to achieve an optimal efficiency goal, the following adjustments are needed:

$$
\begin{gathered}
X_{0}^{* k}=X^{k} \lambda^{* k}=\theta^{* k} X_{0}^{k}-S^{-* k} \\
Y_{0}^{* k}=Y^{k} \lambda^{*(+g k)}=\eta^{* k} Y_{0}^{k}+S^{+g k} \\
Y_{0}^{* k}=Y^{k} \lambda^{*-b k}=\eta^{* k} Y_{0}^{k}+S^{-b k}
\end{gathered}
$$

2.4. Fixed Assets, Labor, Energy Consumption, GDP, Health Expenditure, Birth Rate, Respiratory Diseases, and Mortality Rate Efficiency

In this model, we assess the relative efficiency of decision making units (DMU) based on a DEA method. DMU with good efficiency score merely means that it has a "good rank" in comparison. However, it does not indicate that these municipalities have excellent air quality in the real world. Precisely, the air quality of these municipalities is "comparatively better", thus, these municipalities perform better than other cities in the research sample in air pollutant reduction. In realistic, most cities in China have a large room for improvement in air quality. Since the "Air Pollution Prevention Action Plan" was ordained in China, every city has worked hard on air pollution issues. The cities with good rank in this paper have more chance to succeed in environment protection, due to their comparatively higher air pollution treatment efficiency.

In addition to finding the overall efficiency, the efficiency value for a single input or output can be found. Hu and Wang's [57] total-factor energy efficiency index was adopted to overcome any possible bias in the traditional energy efficiency indicators. There are ten key features in this present study: Fixed assets, Labor, energy consumption, GDP, Health Expenditure, Birth Rate, Respiratory Diseases, Mortality Rate, $\mathrm{CO}_{2}$ and AQI.

In this study, " $\mathrm{I}$ " represents area and " $\mathrm{t}$ " represents time. The ten efficiency models are defined in the following expression:

$$
\text { Fixed assets efficiency }=\frac{\text { Target Fixed Assets input }(i, t)}{\text { Actual Fixed Assets input }(i, t)}
$$




$$
\text { Labor efficiency }=\frac{\text { Target Labor input }(i, t)}{\text { Actual Labor input }(i, t)}
$$

$$
\text { Energy consumption efficiency }=\frac{\text { Target Energy input }(i, t)}{\text { Actual energy input }(i, t)}
$$

$$
\text { GDP efficiency }=\frac{\text { Actual GDP desirable output }(i, t)}{\text { Target GDP desirable output }(i, t)}
$$

$$
\text { Health Expenditure efficiency }=\frac{\text { Target Health Expenditure input }(i, t)}{\text { Actual Health Expenditure input }(i, t)}
$$

$$
\text { Birth Rate efficiency }=\frac{\text { Actual Birth Rate desirable output }(i, t)}{\text { Target Birth Rate desirable output }(i, t)}
$$

Respiratory Diseases efficiency $=\frac{\text { Target Respiratory Diseases Undesirable output }(i, t)}{\text { Actual Respiratory Diseases Undesirable output }(i, t)}$

$$
\begin{aligned}
\text { Mortality Rate efficiency } & =\frac{\text { Target Mortality Rate Undesirable output }(i, t)}{\text { Actual Mortality Rate Undesirable output }(i, t)} \\
\mathrm{CO}_{2} \text { efficiency } & =\frac{\text { Target } \mathrm{CO}_{2} \text { Undesirable output }(\mathrm{i}, \mathrm{t})}{\text { Actual } \mathrm{CO}_{2} \text { Undesirable output }(\mathrm{i}, \mathrm{t})} \\
\text { AQI efficiency } & =\frac{\text { Target AQI Undesirable output }(\mathrm{i}, \mathrm{t})}{\text { Actual AQI Undesirable output }(\mathrm{i}, \mathrm{t})}
\end{aligned}
$$

If the target fixed assets, labor, energy consumption and health expenditure input equals the actual input, then the fixed assets, labor, energy consumption and health expenditure efficiencies equal 1, indicating overall efficiency. If the target fixed assets, labor, energy consumption and health expenditure input is less than the actual input, then the fixed assets, labor, energy consumption and health expenditure efficiencies are less than 1 , indicating overall inefficiency.

If the target GDP and birth rate desirable output is equal to the actual GDP and birth rate desirable output, then the GDP and birth rate efficiency equals 1 , indicating overall efficiency. If the actual GDP and birth rate desirable output is less than the target GDP and birth rate desirable output, then the GDP and birth rate efficiency is less than 1 , indicating overall inefficiency.

If target respiratory diseases, mortality rate, $\mathrm{CO}_{2}$ and $\mathrm{AQI}$ undesirable output is equal to the actual respiratory diseases, mortality rate, $\mathrm{CO}_{2}$ and $\mathrm{AQI}$ undesirable output level, then respiratory diseases, mortality rate, $\mathrm{CO}_{2}$ and $\mathrm{AQI}$ efficiency equals 1 , and is efficient. If target respiratory diseases, mortality rate, $\mathrm{CO}_{2}$ and $\mathrm{AQI}$ undesirable output is less than the actual respiratory diseases, mortality rate, $\mathrm{CO}_{2}$ and AQI undesirable output level, then Mortality Rate efficiency is less than 1, and is inefficient.

\subsection{Data Sources and Description}

This study used panel data for 31 cities of the most developed cities from eastern China to western China. Economics and social development data from 2013 to 2016 were collected from the Statistical Yearbook of China [58], the Demographics and Employment Statistical Yearbook of China, and the City Statistical Yearbooks [59]. Air pollutant data were collected from the China Environmental and Protection Bureau Annual Reports and China Environmental Statistical Yearbook [60]. This study includes the 31 samples; Chengdu, Changsha, Chongqing, Guiyang, Hefei, Huhehot, Kunming, Lanzhou, Lhasa, Nanchang, Nanning, Taiyuan, Wuhan, Urumqi, Xian, Xining, Yinchuan, and Zhengzhou; Beijing, Changchun, Fuzhou, Guangzhou, Harbin, Haikou, Hangzhou, Jinan, Nanjing, Shanghai, Shenyang, Shijiazhuang, and Tianjin (see Figure 1). These 31 cities are all provincial capitals of China's provinces and are distributed in various parts of the Central, East and West China. The core cities representing the economic and social development of China's 31 administrative provinces/municipalities/regions are also the core areas of economic growth and industry of the provinces. Taking these 31 cities as the main research objects, they can represent the actual situation of economic, social and urban development in 
different regions of China, and the policy recommendations and measures proposed in this research can be benefit to the formulation and implementation of policies by the central and local governments.

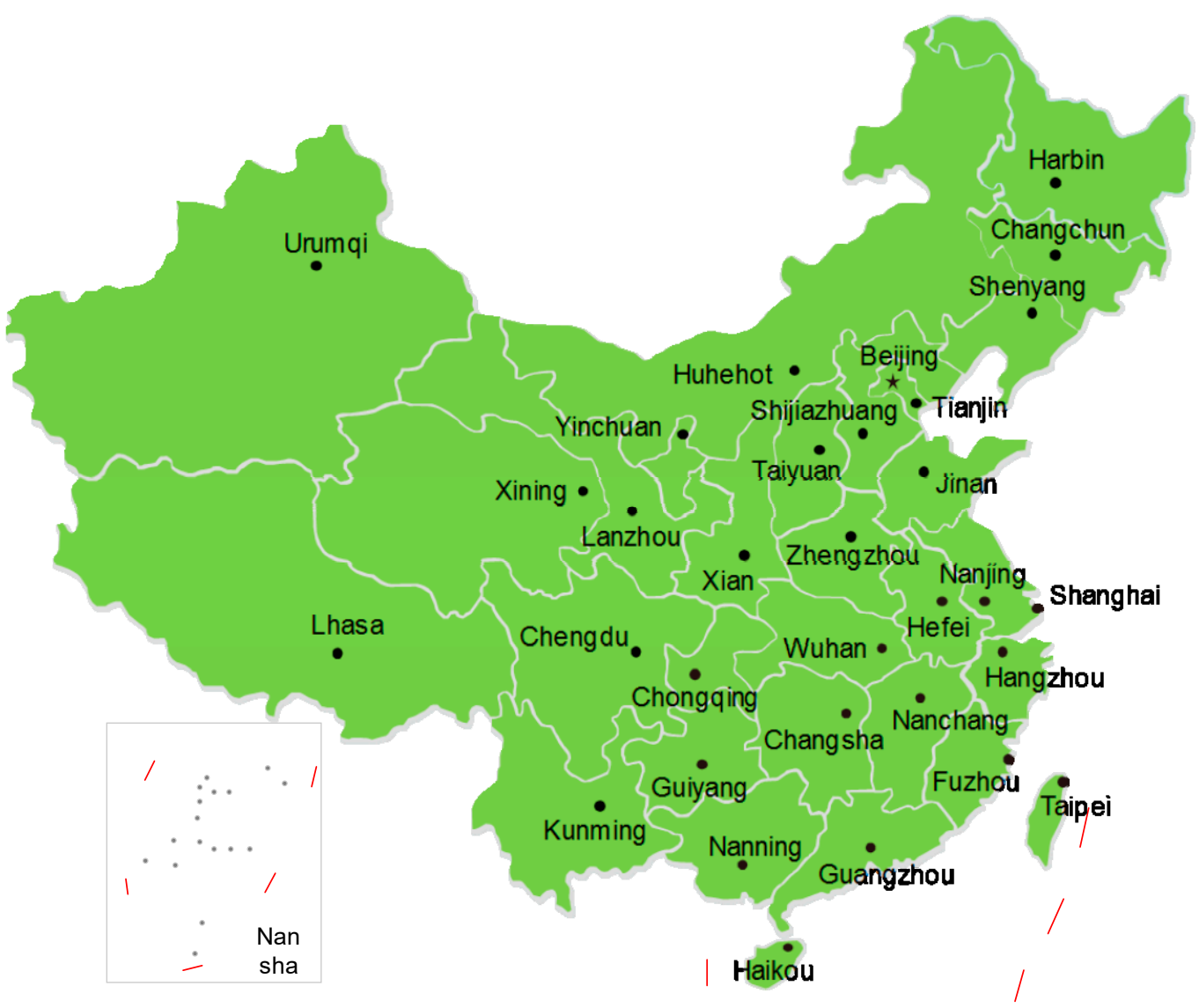

Figure 1. The thirty-one sample cities. (Source: the map is drawn by smart-draw software according to China's National Administrative Planning Map [61]).

Figure 2 shows the framework for the modified undesirable EBM Two-stage DEA Model for efficiency measurement and the variables.
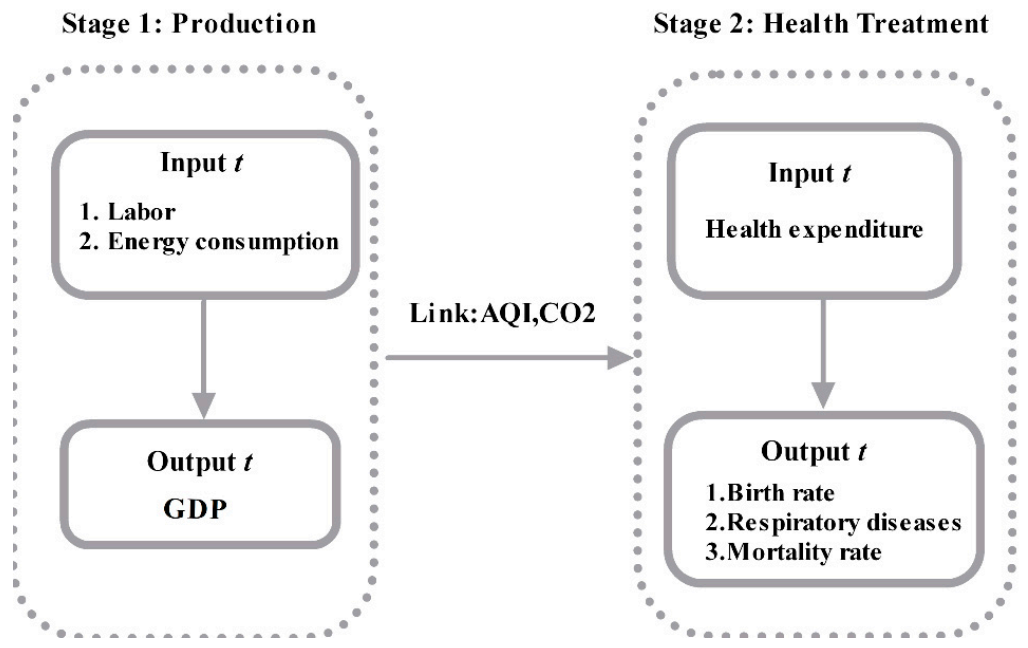

Figure 2. Modified undesirable EBM Two stage DEA.

The input and output variables are outlined in Table 1: 
Table 1. Input and output variables.

\begin{tabular}{cccc}
\hline & Input Variables & Output Variables & Link \\
\hline \multirow{2}{*}{ Stage 1 } & Labor (Lab) & GDP & AQI \\
& $\begin{array}{c}\text { Fixed assets (asset) } \\
\text { Energy consumption (con) }\end{array}$ & $\mathrm{CO}_{2}$ \\
\hline Stage 2 & Health Expenditure & $\begin{array}{c}\text { Birth rate } \\
\text { Respiratory Diseases; } \\
\text { Mortality Rate }\end{array}$ & \\
\hline
\end{tabular}

\subsubsection{Input Variables}

Labor input (lab): employees in each city at the end of each year; unit: person. Fixed Assets (assets): fixed assets investment in each city; unit: 100 million CNY; Energy consumption (con): total energy consumption in each city; unit: 100 million Dun.

\subsubsection{Output Variable}

Desirable output (GDP): GDP in each city; unit: 100 million CNY;

Production Stage and health stage link variables:

Carbon dioxide: $\mathrm{CO}_{2}$; a common greenhouse gas.

The Air quality Index (AQI) is the measured concentration of pollutants; particulate matter $\left(\mathrm{PM}_{2.5}\right.$, $\left.\mathrm{PM}_{10}\right)$, sulfur dioxide $\left(\mathrm{SO}_{2}\right)$, nitrogen dioxide $\left(\mathrm{NO}_{2}\right)$, ozone $\left(\mathrm{O}_{3}\right)$, and carbon monoxide (CO). $\mathrm{PM}_{2.5}$ and $\mathrm{PM}_{10}$ were taken as the 24-h average concentration, and the $\mathrm{CO}_{2}$ emissions data for each city were estimated from the energy consumption breakdown by fuel category.

The second stage: health stage

Input variables: Health Expenditure

Output variables: Birth rate, Respiratory Diseases, Mortality Rate

\section{Results and Discussion}

\subsection{Input-Output Index Statistical Analyses}

Figure 3 shows the labor statistical analysis. From 2013 to 2016, the average value and the maximum value increased slowly, which was related to a decline in youth employment.
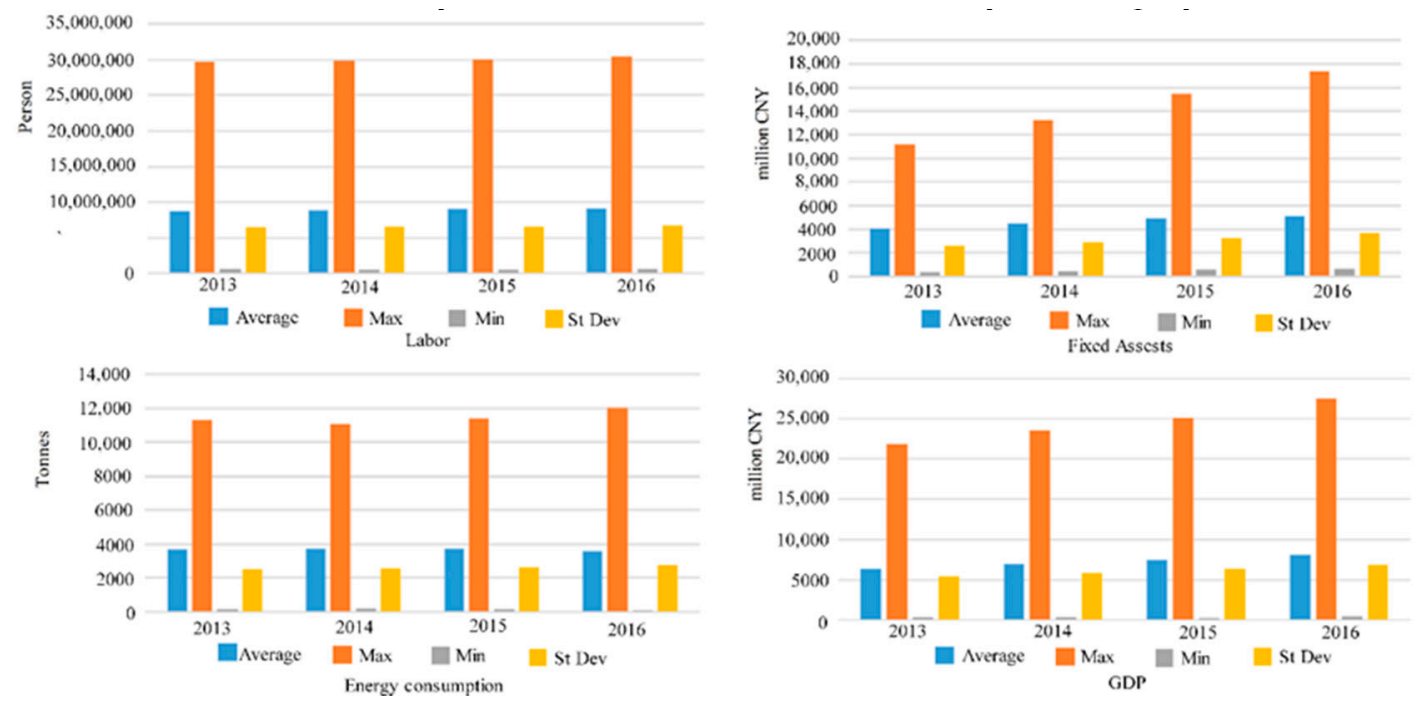

Figure 3. Labor, fixed assets, energy consumptions from 2013-2016. 
The statistical analysis for the fixed assets indicators shows that from 2013 to 2016, the fixed assets input grew rapidly, with the maximum value growing faster than the average value. There were differences in the fixed assets inputs between the cities.

The statistical analysis for the energy consumption indicators from 2013 to 2016 indicates that the maximum value increased in 2013, but declined in 2014, rose again to the level of 2013 in 2015, and increased again in 2016. The minimum value was the highest in 2014, declined in 2015 and further declined in 2016. There were significant energy consumption differences between the cities.

The GDP indicators from 2013 to 2016 illustrate that there was a significant rise in the maximum GDP value. However, because of the minimal increase in the minimum value, the average value increased at a slower rate than the maximum value. There were significant differences in the GDP growth between the cities.

Figure 4 shows the health expenditure indicators and birth rate indicators from 2013 to 2016. As can be seen the government health expenditure input maximum value increased significantly in 2014 and 2015. There was also a large increase in the minimum value, especially in 2016 when the government increased investment.
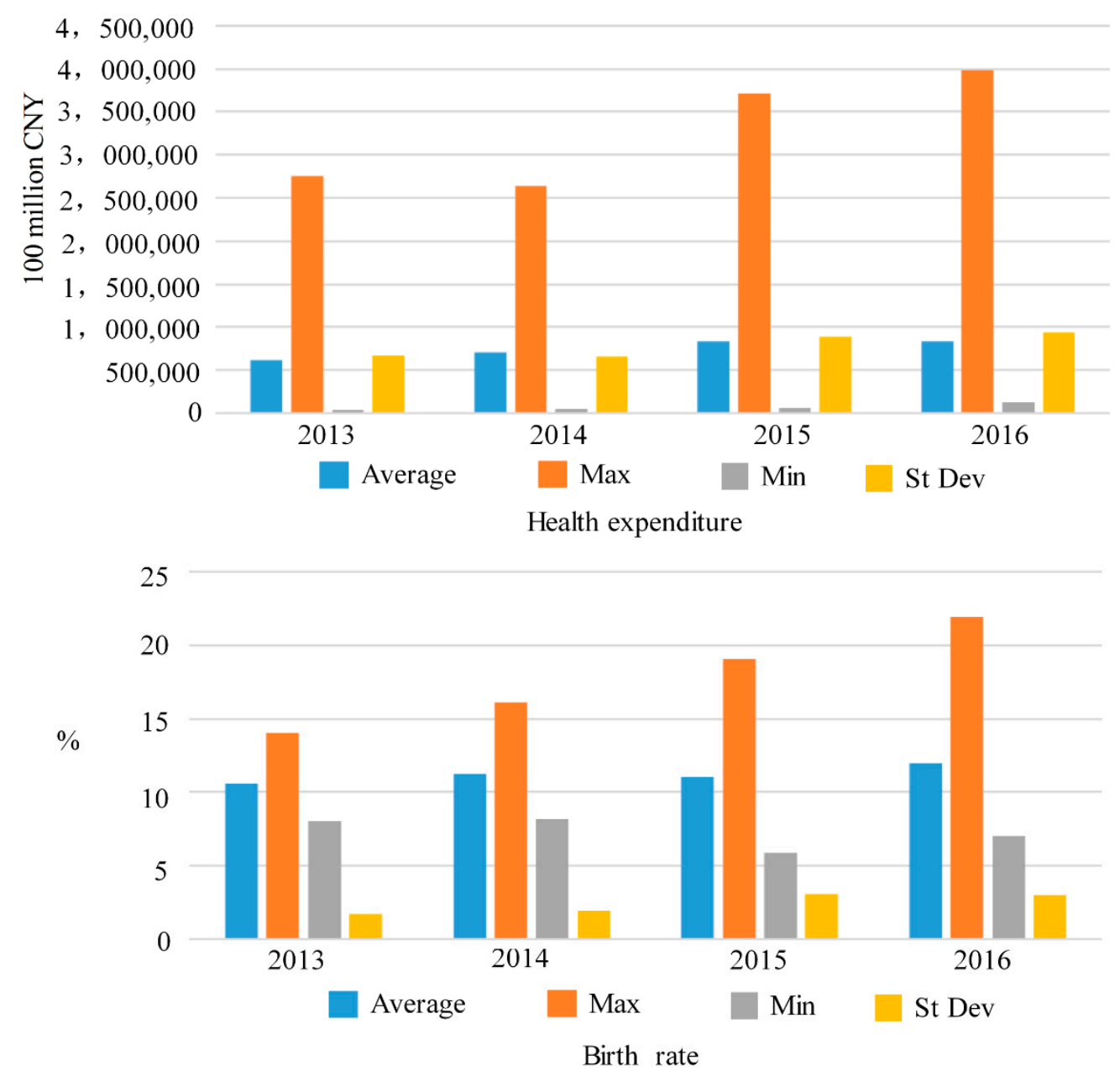

Figure 4. Health expenditures and birth rates from 2013-2016.

The birth rate indicators from 2013 to 2016 from 2013 to 2016 show that the maximum value rose sharply, however, the minimum value first declined to the lowest level in in 2015, but rose again in 2016. 


\subsection{Total City Efficiency Scores for Each Year}

In this paper, we assess the relative efficiency of decision making units based on a undesirable EBM Two-stage DEA method. Table 2 shows the overall efficiency scores for each city from 2013 to 2016. As can be seen, there were significant differences between the cities, with the efficiency scores changing markedly each year.

Table 2. Overall efficiency scores for each city from 2013-2016.

\begin{tabular}{|c|c|c|c|c|c|}
\hline NO & DMU & 2013 & 2014 & 2015 & 2016 \\
\hline 1 & Beijing & 1 & 0.989601 & 1 & 0.849723 \\
\hline 2 & Changchun & 0.815132 & 0.827072 & 0.827642 & 0.608184 \\
\hline 3 & Changsha & 0.89342 & 0.878934 & 0.863749 & 0.902829 \\
\hline 4 & Chengdu & 0.642234 & 0.608838 & 0.66257 & 0.560853 \\
\hline 5 & Chongqing & 0.581473 & 0.594271 & 0.589402 & 0.707737 \\
\hline 6 & Fuzhou & 0.964131 & 0.621109 & 0.934035 & 0.965527 \\
\hline 7 & Guangzhou & 1 & 1 & 1 & 1 \\
\hline 8 & Guiyang & 0.457578 & 0.485777 & 0.488281 & 0.599234 \\
\hline 9 & Harbin & 0.808949 & 0.79447 & 0.796574 & 0.502568 \\
\hline 10 & Haikou & 0.948872 & 0.669205 & 0.928245 & 0.948917 \\
\hline 11 & Hangzhou & 0.843423 & 0.833258 & 0.833978 & 0.843787 \\
\hline 12 & Hefei & 0.77078 & 0.777052 & 0.741251 & 0.97223 \\
\hline 13 & Huhhot & 0.873322 & 0.852322 & 0.790979 & 0.754991 \\
\hline 14 & Jinan & 0.760292 & 0.725372 & 0.653882 & 1 \\
\hline 15 & Kunming & 0.453256 & 0.458886 & 0.50625 & 0.591795 \\
\hline 16 & Lanzhou & 0.525941 & 0.457756 & 0.453991 & 0.682741 \\
\hline 17 & Lhasa & 1 & 1 & 1 & 1 \\
\hline 18 & Nanchang & 0.868581 & 0.84167 & 0.801384 & 0.694567 \\
\hline 19 & Nanjing & 0.8851 & 0.846445 & 0.888145 & 0.802205 \\
\hline 20 & Nanning & 1 & 1 & 1 & 0.865003 \\
\hline 21 & Shanghai & 1 & 1 & 1 & 1 \\
\hline 22 & Shenyang & 0.725947 & 0.686892 & 0.661513 & 0.860712 \\
\hline 23 & Shijiazhuang & 0.456604 & 0.425277 & 0.384795 & 0.459909 \\
\hline 24 & Taiyuan & 0.58708 & 0.49415 & 0.493603 & 0.63538 \\
\hline 25 & Tianjin & 0.823033 & 0.823165 & 0.788025 & 0.664835 \\
\hline 26 & Wuhan & 0.950552 & 0.789078 & 0.771077 & 0.766357 \\
\hline 27 & Urumqi & 0.916579 & 0.893509 & 0.594525 & 0.984552 \\
\hline 28 & Xian & 0.654069 & 0.65707 & 0.615445 & 0.598831 \\
\hline 29 & Xining & 0.508144 & 0.435087 & 0.428298 & 0.590434 \\
\hline 30 & Yinchuan & 0.646088 & 0.589195 & 0.572028 & 0.767119 \\
\hline 31 & Zhengzhou & 0.904107 & 0.914056 & 0.928053 & 0.706123 \\
\hline
\end{tabular}

Of the 31 cities, only Guangzhou and Shanghai had efficiency scores of 1 in all four years, Lhasa and Nanning had efficiency scores of 1 in the first three years, but then fell to 0.86 in 2016. Beijing's efficiency score was 1 in 2013 and 2015 but it declined slightly in 2014 and 2016.

As can be seen in Figure 4, only Kunming had an overall efficiency score that continued to rise across all four years, Chongqing and Guiyang has four-year upward fluctuations, and Changchun and Zhengzhou has increasing overall efficiency in the first three years but declined in the last year. Generally, this analysis indicated that the overall efficiency improvements in most cities was poor, with the total efficiency in only Chongqing and Guiyang improving over the four years.

Huhehot, Nanchang, Nanning, Tianjin, Wuhan, and Xian all had continuous decreases in overall efficiency across the four years; therefore, the need for improvement was expanding. Xining, Yinchuan, Changsha, Jinan, Shenyang, Lanzhou, Shijiazhuang, and Taiyuan had rising overall efficiencies in the first three years but suffered declines in 2016. 


\subsection{Comparison of the Radial and Non-Radial Non-Efficiency Scores in Each City}

As shown in Table 3, the Epsilon scores for the inputs and outputs were all below 0.5, indicating that all data were suitable for the radial input analysis of the efficiency evaluation.

Table 3. Epsilon Scores from 2013-2016.

\begin{tabular}{ccccc}
\hline & $\mathbf{2 0 1 3}$ & $\mathbf{2 0 1 4}$ & $\mathbf{2 0 1 5}$ & $\mathbf{2 0 1 6}$ \\
\hline Epsilon for EBMX & 0.057 & 0.051 & 0.095 & 0.1119 \\
Epsilon for y & 0.3594 & 0.2465 & 0.242 & 0.2667 \\
\hline
\end{tabular}

Our research analyzes the efficiency of various indicators including: Fixed assets, Labor, energy consumption, GDP, Health Expenditure, Birth Rate, Respiratory Diseases, Mortality Rate, $\mathrm{CO}_{2}$ and AQI related to energy consumption and environmental pollution and inputs in government medical treatment. On the other hand, this paper evaluates and compares the input and output efficiency of local governments in energy, environment and health management, and analyze the room for improvement of resource utilization to improve the efficiency and fairness of resource allocation between central and local governments.

\subsection{3 to 2016 Efficiency Scores and Rankings for Labor, Fixed Assets, and Energy Consumption}

As shown in Table 4, Guangzhou, Lhasa, Nanning and Shanghai had labor efficiencies of 1; therefore, there was no need for further improvement.

However, only Guiyang and Haikou has improving labor efficiency scores from 2013 to 2016. Chengdu, Chongqing, Harbin, Nanchang, Shijiazhuang, Tianjin, Wuhan, Xian, Yinchuan, Zhengzhou all had falling labor efficiencies, indicating that more improvements were necessary. The labor efficiencies in some other cities were fluctuating but fell in 2016.

Guangzhou, Lhasa, and Shanghai all had fixed assets efficiency scores of 1 from 2013 to 2016; therefore, there was no further need for improvements. Hefei, Huhehot, Nanjing, Xian and Shenyang all had rising fixed assets efficiencies; however, the other 23 cities had declining or fluctuating fixed asset indicators. Nanning had a fixed asset efficiency of 1 in the first three years; however, it fell to around 0.59 in 2016, and there was a significant need for improvement.

From 2013 to 2016, the energy consumption efficiencies in Guiyang, Lanzhou and Hangzhou continued to increase. Chongqing, Fuzhou, Haikou, Hangzhou, Hefei, Huhehot, Jinan, Kunming, Nanjing, Shenyang, Tianjin, Xining, and Urumqi had upwardly fluctuating energy consumption efficiencies, with Jinan and Shenyang having larger increases; Jinan's efficiency score increased from 0.5 in 2013 to 1 in 2016, and Shenyang's rose from 0.6 in 2013 to 1 in 2016.

The energy consumption efficiencies in Harbin, Nanchang, Nanning, Xian, and Yinchuan continued to decline, and the energy efficiencies in the other 10 cities had downward fluctuating trends. Except for eight cities, the fixed assets and employment efficiency scores were declining of had downward fluctuating trends.

\subsection{3 to 2016 Health Expenditure, GDP, and Birth Rate Efficiency Scores and Rankings}

Beijing, Wuhan, Xining, and Nanning government health expenditure input indicators dropped significantly; however, in most other cities, health expenditure efficiency had a continuous increase or upward fluctuating trends, indicating that the need for improvements was shrinking. Changsha, Chengdu, Chongqing, Guiyang, Hangzhou, Hefei, Jinan, Nanjing and Tianjin all had larger efficiency increases, with Tianjin's efficiency rising from 0.1 in 2013 to around 0.7 in 2016, Jinan's rising from 0.3 in 2013 to 1 in 2016, and Hefei's rising from 0.43 in 2013 to 1 in 2016. Changchun, Harbin, Huhehot, Kunming, Nanchang, Shenyang, Shijiazhuang, Taiyuan, Xian, and Zhengzhou had lower efficiency rises than the above nine cities. 
Table 4. Employment, fixed assets investment, and energy consumption efficiency scores.

\begin{tabular}{|c|c|c|c|c|c|c|c|c|c|c|c|c|c|}
\hline No. & DMU & 2013 Em & $2014 \mathrm{Em}$ & 2015 Em & 2016 Em & 2013 Asset & 2014 Asset & 2015 Asset & 2016 Asset & 2013 Com & 2014 Com & 2015 Com & 2016 Com \\
\hline 1 & Beijing & 1 & 0.880763374 & 1 & 0.8524 & 1 & 0.9592901 & 1 & 0.9210143 & 1 & 0.99542 & 1 & 0.99856 \\
\hline 2 & Changchun & 0.8991 & 0.90611047 & 0.90711 & 0.8057 & 0.7215939 & 0.7411042 & 0.744306 & 0.6096182 & 0.8991 & 0.90611 & 0.907108 & 0.80574 \\
\hline 3 & Changsha & 0.94709 & 0.938663441 & 0.93327 & 0.952 & 0.5721516 & 0.5235194 & 0.460713 & 0.4841279 & 0.65715 & 0.66672 & 0.664614 & 0.65718 \\
\hline 4 & Chengdu & 0.78317 & 0.757419183 & 0.7979 & 0.7446 & 0.6087696 & 0.6515081 & r & 0.6197391 & 0.78317 & 0.75742 & 0.797897 & 0.74458 \\
\hline 5 & Chongqing & 0.63104 & 0.500024235 & 0.52621 & 0.5274 & 0.5582939 & 0.4286548 & 0.421291 & 0.3855462 & 0.7371 & 0.74854 & 0.747195 & 0.75362 \\
\hline 6 & Fuzhou & 1 & 0.733257885 & 1 & 1 & 0.8617823 & 0.5204487 & 0.641657 & 0.6194099 & 1 & 0.76774 & 1 & 1 \\
\hline 7 & Guangzhou & 1 & 1 & 1 & 1 & 1 & 1 & 1 & 1 & 1 & 1 & 1 & 1 \\
\hline 8 & Guiyang & 0.62894 & 0.654998838 & 0.65875 & 0.6882 & 0.6146963 & 0.5623476 & 0.485601 & 0.4681071 & 0.47867 & 0.55585 & 0.591906 & 0.61108 \\
\hline 9 & Harbin & 0.89606 & 0.885502631 & 0.88703 & 0.7242 & 0.5813495 & 0.8774743 & 0.857175 & 0.6756626 & 0.89606 & 0.8855 & 0.887034 & 0.73003 \\
\hline 11 & Hangzhou & 0.91704 & 0.910943901 & 0.91314 & 0.9319 & 0.7152775 & 0.6503048 & 0.608121 & 0.6141956 & 0.73959 & 0.76052 & 0.798248 & 0.80345 \\
\hline 12 & Hefei & 0.87244 & 0.876119794 & 0.85484 & 1 & 0.5259938 & 0.5418133 & 0.477602 & 0.5705747 & 0.87244 & 0.87612 & 0.85484 & 1 \\
\hline 13 & Huhehot & 0.93601 & 0.921804653 & 0.88594 & 0.9181 & 0.7780742 & 0.756976 & 0.753144 & 0.8292995 & 0.38497 & 0.75263 & 0.724236 & 0.69614 \\
\hline 14 & Jinan & 0.86547 & 0.84230184 & 0.79403 & 1 & 0.8654708 & 0.8423018 & 0.695281 & 1 & 0.56354 & 0.54639 & 0.554859 & 1 \\
\hline 15 & Kunming & 0.62511 & 0.630134621 & 0.67327 & 0.6673 & 0.5159696 & 0.544736 & 0.571462 & 0.5270656 & 0.53329 & 0.53631 & 0.673272 & 0.66728 \\
\hline 16 & Lanzhou & 0.69119 & 0.62970179 & 0.62858 & 0.6486 & 0.6911945 & 0.6297018 & 0.607536 & 0.5982818 & 0.39525 & 0.34542 & 0.284083 & 0.31471 \\
\hline 17 & Lhasa & 1 & 1 & 1 & 1 & 1 & 1 & 1 & 1 & 1 & 1 & 1 & 1 \\
\hline 18 & Nanchang & 0.93126 & 0.915454664 & 0.89282 & 0.8131 & 0.6223186 & 0.6027086 & 0.543299 & 0.4671772 & 0.93126 & 0.91545 & 0.892823 & 0.81313 \\
\hline 19 & Nanjing & 0.94253 & 0.920028875 & 0.94426 & 0.9628 & 0.5596182 & 0.5317071 & 0.588637 & 0.6139003 & 0.64366 & 0.61318 & 0.884983 & 0.86169 \\
\hline 22 & Shenyang & 0.84477 & 0.817273553 & 0.80052 & 1 & 0.4111169 & 0.4090846 & 0.52199 & 1 & 0.64117 & 0.64932 & 0.63962 & 1 \\
\hline 23 & Shijiazhuang & 0.62809 & 0.597933513 & 0.55923 & 0.576 & 0.6155488 & 0.5774181 & 0.440956 & 0.4641232 & 0.4664 & 0.42375 & 0.378611 & 0.38869 \\
\hline 24 & Taiyuan & 0.74324 & 0.664259912 & 0.66666 & 0.6827 & 0.7432409 & 0.6642599 & 0.642631 & 0.6826506 & 0.17809 & 0.17449 & 0.168238 & 0.20609 \\
\hline 25 & Tianjin & 0.90639 & 0.906020087 & 0.8873 & 0.9113 & 0.4624992 & 0.4587871 & 0.420641 & 0.4033572 & 0.69375 & 0.70324 & 0.700194 & 0.67872 \\
\hline 26 & Wuhan & 0.976 & 0.884533161 & 0.87519 & 0.8883 & 0.7022254 & 0.5266488 & 0.497459 & 0.559047 & 0.976 & 0.7285 & 0.760198 & 0.74618 \\
\hline 27 & Urumqi & 0.95647 & 0.904900248 & 0.74691 & 0.9753 & 0.956474 & 0.943938 & 0.701972 & 1 & 0.95647 & 0.94394 & 0.672827 & 1 \\
\hline 28 & Xian & 0.79259 & 0.794542591 & 0.76402 & 0.733 & 0.4964975 & 0.4999415 & 0.553458 & 0.585522 & 0.79259 & 0.79454 & 0.764021 & 0.73304 \\
\hline 29 & Xining & 0.67649 & 0.608688283 & 0.60402 & 0.6183 & 0.6764852 & 0.5877194 & 0.588659 & 0.5693241 & 0.2649 & 0.23926 & 0.244148 & 0.56395 \\
\hline 30 & Yinchuan & 0.78832 & 0.744749892 & 0.7347 & 0.75 & 0.6361415 & 0.547706 & 0.522813 & 0.50217 & 0.37095 & 0.33598 & 0.272031 & 0.2703 \\
\hline 31 & Zhengzhou & 0.95091 & 0.956111727 & 0.96513 & 0.8493 & 0.7003059 & 0.7250648 & 0.667886 & 0.5763073 & 0.95091 & 0.95611 & 0.965132 & 0.84935 \\
\hline
\end{tabular}


Table 5. Health expenditure, GDP, and birth rate.

\begin{tabular}{|c|c|c|c|c|c|c|c|c|c|c|c|c|c|}
\hline No. & DMU & 2013 Gov & 2014 Gov & 2015 Gov & 2016 Gov & 2013 GDP & 2014 GDP & 2015 GDP & 2016 GDP & 2013 Birth & 2014 Birth & 2015 Birth & 2016 Birth \\
\hline 1 & Beijing & 1 & 0.96094 & 0.05671 & 0.5166 & 1 & 0.995465 & 1 & 0.99857 & 1 & 0.963767 & 0.789418 & 0.88558 \\
\hline 2 & Changchun & 0.25316 & 0.46671 & 0.47856 & 0.3657 & 0.91604 & 0.920954 & 0.92166 & 0.86009 & 0.852579 & 0.82427 & 0.789224 & 0.82091 \\
\hline 3 & Changsha & 0.59978 & 0.94384 & 0.93633 & 0.9537 & 0.95215 & 0.945366 & 0.94113 & 0.9562 & 0.77771 & 0.949508 & 0.943526 & 0.95765 \\
\hline 4 & Chengdu & 0.24204 & 0.78878 & 0.77694 & 0.6993 & 0.84876 & 0.836664 & 0.85607 & 0.83094 & 0.789178 & 0.851511 & 0.845755 & 0.81222 \\
\hline 5 & Chongqing & 0.26016 & 0.47816 & 0.22884 & 0.9113 & 0.8277 & 0.832685 & 0.83209 & 0.83495 & 0.856535 & 0.852643 & 0.827296 & 0.92465 \\
\hline 6 & Fuzhou & 1 & 1 & 1 & 1 & 0.82228 & 0.841409 & 0.70848 & 0.71394 & 1 & 1 & 1 & 1 \\
\hline 7 & Guangzhou & 1 & 1 & 1 & 1 & 1 & 1 & 1 & 1 & 1 & 1 & 1 & 1 \\
\hline 8 & Guiyang & 0.48762 & 0.61125 & 0.77832 & 0.814 & 0.78701 & 0.795858 & 0.79718 & 0.80797 & 0.873615 & 0.871849 & 0.846413 & 0.86444 \\
\hline 9 & Harbin & 0.25863 & 0.3673 & 0.34956 & 0.3512 & 0.91395 & 0.906837 & 0.90785 & 0.82469 & 0.7861 & 0.7448 & 0.750149 & 0.78346 \\
\hline 11 & Hangzhou & 0.27926 & 0.87943 & 0.74457 & 0.9093 & 0.92885 & 0.924408 & 0.92599 & 0.94004 & 0.828756 & 0.902858 & 0.830937 & 0.92326 \\
\hline 12 & Hefei & 0.43444 & 0.43593 & 0.84694 & 1 & 0.89837 & 0.900718 & 0.8875 & 0.74737 & 0.798231 & 0.775016 & 0.904677 & 1 \\
\hline 13 & Huhehot & 0.67207 & 0.78388 & 0.66767 & 0.8061 & 0.94327 & 0.93238 & 0.90713 & 0.9296 & 0.854945 & 0.849102 & 0.805043 & 0.86027 \\
\hline 14 & Jinan & 0.31353 & 0.52193 & 0.74403 & 1 & 0.89399 & 0.880114 & 0.85412 & 1 & 0.7962 & 0.802036 & 0.830702 & 1 \\
\hline 15 & Kunming & 0.68631 & 0.84896 & 0.77153 & 0.7134 & 0.78575 & 0.787401 & 0.8024 & 0.80022 & 0.975447 & 0.884002 & 0.843185 & 0.87089 \\
\hline 16 & Lanzhou & 0.62664 & 0.84152 & 0.78017 & 0.666 & 0.8091 & 0.787258 & 0.78689 & 0.79364 & 1 & 1 & 0.847304 & 0.98908 \\
\hline 17 & Lhasa & 1 & 1 & 1 & 1 & 1 & 1 & 1 & 1 & 1 & 1 & 1 & 1 \\
\hline 18 & Nanchang & 0.41275 & 0.50408 & 0.59055 & 0.5141 & 0.93957 & 0.927683 & 0.91174 & 0.86397 & 0.869366 & 0.875546 & 0.846009 & 0.879 \\
\hline 19 & Nanjing & 0.29595 & 0.88139 & 0.72304 & 0.8249 & 0.94845 & 0.931056 & 0.94985 & 0.96537 & 0.807256 & 0.904131 & 0.821769 & 0.87031 \\
\hline 22 & Shenyang & 0.56643 & 0.71526 & 0.49546 & 0.8638 & 0.88155 & 0.866179 & 0.85741 & 1 & 0.767789 & 0.818579 & 0.748871 & 0.89298 \\
\hline 23 & Shijiazhuang & 0.35585 & 0.37972 & 0.7867 & 0.6887 & 0.78673 & 0.777141 & 0.76574 & 0.77057 & 0.813034 & 0.821527 & 0.850482 & 0.80813 \\
\hline 24 & Taiyuan & 0.73754 & 0.7174 & 0.79461 & 0.877 & 0.83036 & 0.799136 & 0.8 & 0.80587 & 0.860941 & 0.885525 & 0.854415 & 0.9013 \\
\hline 25 & Tianjin & 0.0753 & 0.55627 & 0.45309 & 0.6951 & 0.92116 & 0.92089 & 0.90803 & 0.92469 & 0.814586 & 0.793887 & 0.794337 & 0.81061 \\
\hline 26 & Wuhan & 1 & 0.72251 & 0.58542 & 0.8523 & 0.9771 & 0.906196 & 0.90012 & 0.9087 & 1 & 0.87223 & 0.880181 & 0.88597 \\
\hline 27 & Urumqi & 1 & 1 & 0.95092 & 1 & 0.95996 & 0.94959 & 0.83197 & 0.80415 & 1 & 1 & 0.95531 & 1 \\
\hline 28 & Xian & 0.25664 & 0.37726 & 0.68999 & 0.626 & 0.8534 & 0.85438 & 0.83968 & 0.82596 & 0.804754 & 0.88843 & 0.828994 & 0.84331 \\
\hline 29 & Xining & 0.87413 & 0.93019 & 0.83717 & 0.6702 & 0.80358 & 0.780485 & 0.77902 & 0.78355 & 0.899443 & 0.945976 & 0.87717 & 0.89988 \\
\hline 30 & Yinchuan & 0.97799 & 0.94424 & 0.89527 & 0.9838 & 0.85128 & 0.831016 & 0.82667 & 0.83332 & 0.987265 & 0.988725 & 0.913409 & 0.99467 \\
\hline 31 & Zhengzhou & 0.20557 & 0.27189 & 0.4091 & 0.3529 & 0.9553 & 0.959653 & 0.9674 & 0.88423 & 0.867986 & 0.863565 & 0.891459 & 0.87214 \\
\hline
\end{tabular}


Table 6. Respiratory disease mortality efficiency scores.

\begin{tabular}{|c|c|c|c|c|c|c|c|c|c|}
\hline No. & DMU & 2013 Respiratory Diseases & 2014 Respiratory Diseases & 2015 Respiratory Diseases & 2016 Respiratory Diseases & 2013 Mort & 2014 Mort & 2015 Mort & 2015 Mort \\
\hline 1 & Beijing & 1 & 0.9351834 & 0.7547981 & 0.8173057 & 1 & 0.960936 & 0.780715 & 0.851629 \\
\hline 2 & Changchun & 0.7845439 & 0.7290381 & 0.6356186 & 0.7209566 & 0.790939 & 0.729038 & 0.635619 & 0.720957 \\
\hline 3 & Changsha & 0.5985419 & 0.943837 & 0.9363347 & 0.93773943 & 0.599781 & 0.943837 & 0.936335 & 0.953731 \\
\hline 4 & Chengdu & 0.353543 & 0.5248746 & 0.5263787 & 0.40725183 & 0.635481 & 0.788785 & 0.776945 & 0.699285 \\
\hline 5 & Chongqing & 0.7850896 & 0.7910674 & 0.7361652 & 0.87849315 & 0.798806 & 0.791067 & 0.736165 & 0.91128 \\
\hline 6 & Fuzhou & 1 & 1 & 1 & 1 & 1 & 1 & 1 & 1 \\
\hline 7 & Guangzhou & 1 & 1 & 1 & 1 & 1 & 1 & 1 & 1 \\
\hline 8 & Guiyang & 0.8285099 & 0.8276835 & 0.7783176 & 0.81401447 & 0.830862 & 0.827684 & 0.778318 & 0.814014 \\
\hline 9 & Harbin & 0.6223008 & 0.4787582 & 0.5005972 & 0.61802974 & 0.62618 & 0.478758 & 0.496996 & 0.61803 \\
\hline 10 & Haikou & 1 & 1 & 1 & 1 & 1 & 1 & 1 & 1 \\
\hline 11 & Hangzhou & 0.5968402 & 0.8078024 & 0.6509197 & 0.63179293 & 0.739557 & 0.879434 & 0.744569 & 0.909349 \\
\hline 12 & Hefei & 0.6587714 & 0.590962 & 0.8822236 & 1 & 0.661724 & 0.590962 & 0.882224 & 1 \\
\hline 13 & Huhehot & 0.7929696 & 0.7838774 & 0.6804446 & 0.80607653 & 0.795665 & 0.783877 & 0.680445 & 0.806076 \\
\hline 14 & Jinan & 0.651048 & 0.6722845 & 0.7440329 & 1 & 0.655975 & 0.672285 & 0.744033 & 1 \\
\hline 15 & Kunming & 0.8505386 & 0.8489619 & 0.7715309 & 0.78514154 & 0.974179 & 0.848962 & 0.771531 & 0.825943 \\
\hline 16 & Lanzhou & 0.999649 & 1 & 0.7801701 & 0.98883699 & 1 & 1 & 0.78017 & 0.988837 \\
\hline 17 & Lhasa & 1 & 1 & 1 & 1 & 1 & 1 & 1 & 1 \\
\hline 18 & Nanchang & 0.8216687 & 0.8343026 & 0.7774755 & 0.84036978 & 0.823165 & 0.834303 & 0.777475 & 0.84037 \\
\hline 19 & Nanjing & 0.6809365 & 0.881388 & 0.7230441 & 0.70638892 & 0.686346 & 0.881388 & 0.723044 & 0.824899 \\
\hline 20 & Nanning & 1 & 1 & 1 & 1 & 1 & 1 & 1 & 0.987957 \\
\hline 21 & Shanghai & 1 & 1 & 1 & 1 & 1 & 1 & 1 & 1 \\
\hline 22 & Shenyang & 0.5664307 & 0.7152643 & 0.4954621 & 0.56899178 & 0.524542 & 0.629656 & 0.436969 & 0.557693 \\
\hline 23 & Shijiazhuang & 0.6946655 & 0.7224598 & 0.7866965 & 0.64157819 & 0.701364 & 0.72246 & 0.786697 & 0.688659 \\
\hline 24 & Taiyuan & 0.8035407 & 0.8515336 & 0.7946128 & 0.87701927 & 0.807366 & 0.851534 & 0.794611 & 0.877019 \\
\hline 25 & Tianjin & 0.6923424 & 0.6493323 & 0.6506331 & 0.6523241 & 0.705305 & 0.649332 & 0.650633 & 0.695142 \\
\hline 26 & Wuhan & 1 & 0.8283719 & 0.8424187 & 0.84428669 & 1 & 0.803032 & 0.842419 & 0.852283 \\
\hline 27 & Urumqi & 1 & 1 & 0.8202437 & 1 & 1 & 1 & 0.950923 & 1 \\
\hline 28 & Xian & 0.6739938 & 0.8563826 & 0.7401074 & 0.76480002 & 0.679666 & 0.577883 & 0.740107 & 0.771797 \\
\hline 29 & Xining & 0.8740992 & 0.939432 & 0.8371692 & 0.87480972 & 0.874129 & 0.939432 & 0.83714 & 0.86864 \\
\hline 30 & Yinchuan & 0.9857324 & 0.9884652 & 0.8952715 & 0.99461062 & 0.986932 & 0.988465 & 0.895263 & 0.992445 \\
\hline 31 & Zhengzhou & 0.8206256 & 0.8123653 & 0.8613643 & 0.61338284 & 0.769943 & 0.730502 & 0.861364 & 0.828208 \\
\hline
\end{tabular}


There were less cities with higher GDP efficiencies that cities with rising GDP efficiencies. Chongqing, Guiyang, Hangzhou, Jinan, Kunming and Shenyang had rising GDP efficiencies; however, Changchun, Fuzhou, Harbin, Haikou, Hefei, Huhehot, Nanchang, Nanning, Wuhan, Urumqi, and Xian all experienced significant GDP efficiency declines, indicating that the need for GDP efficiency improvements was expanding.

Fuzhou, Guangzhou, Haikou, Lhasa, Nanning, and Shanghai all had birth rate efficiencies of 1 for all four years from 2013-2016; however, Beijing, Changchun, Shenyang, Kunming, Lanzhou, Shijiazhuang, and Wuhan had continuous downward fluctuations. The birth rate efficiencies in the other 28 cities continued to rise or had an upward fluctuation, with Changsha, Hefei, Jinan, and Shenyang experiencing larger increases (Table 5).

\subsection{3 to 2016 Respiratory Diseases and Mortality Rate Efficiency Scores and Rankings}

Table 6 shows that Beijing, Changchun, Guiyang, Harbin, Kunming, Lanzhou, Shijiazhuang, Tianjin, Wuhan, and Zhengzhou all had decreasing respiratory disease efficiencies, with Beijing, Zhengzhou, and Wuhan experiencing the largest falls, with Beijing, falling from 1 in 2013 to 0.82 in 2016, and Wuhan falling from 1 in 2013 to 0.84 in 2016. However, in the other cities, the respiratory diseases efficiencies were rising, with Changsha, Chongqing, Hefei, and Jinan experiencing larger increases. Hefei and Jinan's respiratory diseases efficiencies rose from around 0.65 in 2013 to 1 in 2016, and Changsha's rose from 0.6 in 2013 to 0.94 in 2016.

There were large differences in the mortality rate efficiency improvements between the cities from 2013 to 2016. Fuzhou, Guangzhou, Haikou, Lhasa, and Shanghai all had mortality rate efficiencies of 1, and Changsha, Chongqing, Hefei, Hangzhou, Jinan, and Nanjing had large increases; Hefei and Jinan's mortality rate efficiencies rose from 0.61 in 2013 to 1 in 2016, Hangzhou's rose from 0.74 in 2012 to 0.93 in 2016, and Nanjing's rose from 0.69 in 2013 to 0.91 in 2016.

A further 15 cities had upward mortality rate efficiency trends but there were 11 cities with reduced mortality rate efficiencies. Overall, there were more cities with improved mortality rate efficiencies than cities with reduced efficiencies.

\subsection{3 to 2016 CO2 and AQI Efficiency Scores and Rankings}

As shown in Table 7, Fuzhou, Guangzhou, Haikou, Lhasa, and Shanghai all achieved carbon dioxide and AQI emissions efficiency scores of 1 , indicating that there was no need for further carbon emissions and air pollution emissions improvements. Zhengzhou, Yinchuan, Xian, Tianjin, Wuhan, Shijiazhuang, Nanning, Nanchang, Huhehot, Harbin and Changchun all had large fluctuations with falling $\mathrm{CO}_{2}$ emissions efficiencies, of which Harbin's fell the most from around 0.9 in 2013 to around 0.73 in 2016.

The carbon emissions efficiencies in the other 15 cities all increased over the four years, with Jinan, Shenyang and Xining experiencing large improvements; Jinan's rose from 0.56 in 2013 to 1 in 2016, Shenyang's rose from 0.67 in 2013 to 1 in 2016, and Xining's rose from 0.27 in 2013 to 0.56 in 2016.

Chongqing, Guangzhou, Fuzhou, Haikou, Nanning, Shanghai, and Lhasa had AQI emissions efficiency of 1 in all four years, and therefore there were no further improvements needed. Twelve cities had downward AQI emissions efficiency trends; Shijiazhuang's dropped from 0.82 in 2013 to 0.49 in 2016, Xining's dropped from 0.74 in 2013 to 0.48 in 2016, Nanchang's fluctuated from 1 in 2013 to 0.83 in 2016, and Nanjing's dropped from 0.936 in 2013 to 0.778 in 2016.

The AQI emissions efficiencies in Jinan, Shenyang and Urumqi fluctuated significantly, with all having efficiencies of 1 in 2013, 2014 and 2016; however, in 2015, the AQI emissions efficiencies dropped significantly to around 0.40 . 
Table 7. 2013-2016 AQI treatment and carbon dioxide emission treatment efficiency scores.

\begin{tabular}{|c|c|c|c|c|c|c|c|c|c|}
\hline No. & DMU & $2013 \mathrm{CO}_{2}$ & $2014 \mathrm{CO}_{2}$ & $2015 \mathrm{CO}_{2}$ & $2016 \mathrm{CO}_{2}$ & 2013 AQI & 2014 AQI & $2015 \mathrm{AQI}$ & 2016 AQI \\
\hline 1 & Beijing & 1 & 0.987029 & 1 & 0.99856 & 1 & 1 & 1 & 0.911188 \\
\hline 2 & Changchun & 0.93627 & 0.872525 & 0.90711 & 0.80574 & 1 & 1 & 0.51444 & 0.787896 \\
\hline 3 & Changsha & 0.66249 & 0.662893 & 0.66461 & 0.65718 & 1 & 1 & 0.66639 & 1 \\
\hline 4 & Chengdu & 0.7123 & 0.830107 & 0.7979 & 0.74458 & 1 & 1 & 0.72416 & 0.85539 \\
\hline 5 & Chongqing & 0.70269 & 0.772805 & 0.74719 & 0.75362 & 1 & 1 & 1 & 1 \\
\hline 6 & Fuzhou & 1 & 1 & 1 & 1 & 1 & 1 & 1 & 1 \\
\hline 7 & Guangzhou & 1 & 1 & 1 & 1 & 1 & 1 & 1 & 1 \\
\hline 8 & Guiyang & 0.53085 & 0.504128 & 0.73552 & 0.61108 & 1 & 1 & 0.65398 & 1 \\
\hline 9 & Harbin & 0.90319 & 0.875912 & 0.88703 & 0.73003 & 0.67555 & 1 & 0.65821 & 1 \\
\hline 10 & Haikou & 1 & 1 & 1 & 1 & 1 & 1 & 1 & 1 \\
\hline 11 & Hangzhou & 0.75835 & 0.744039 & 0.79825 & 0.80345 & 1 & 1 & 0.57907 & 0.722116 \\
\hline 12 & Hefei & 0.87818 & 0.872797 & 0.85484 & 1 & 0.75795 & 1 & 0.4995 & 1 \\
\hline 13 & Huhehot & 0.75483 & 0.384172 & 0.72424 & 0.69614 & 1 & 0.87452 & 0.41833 & 1 \\
\hline 14 & Jinan & 0.55995 & 0.546146 & 0.55486 & 1 & 1 & 1 & 0.40835 & 1 \\
\hline 15 & Kunming & 0.53348 & 0.535843 & 0.67327 & 0.66728 & 1 & 1 & 0.92484 & 1 \\
\hline 16 & Lanzhou & 0.38517 & 0.347773 & 0.28408 & 0.31471 & 0.78338 & 0.55009 & 0.43372 & 0.471312 \\
\hline 17 & Lhasa & 1 & 1 & 1 & 1 & 1 & 1 & 1 & 1 \\
\hline 18 & Nanchang & 0.9182 & 0.93236 & 0.89282 & 0.81313 & 1 & 1 & 0.68149 & 0.829057 \\
\hline 19 & Nanjing & 0.61562 & 0.645276 & 0.88498 & 0.86169 & 0.9357 & 1 & 0.62126 & 0.778348 \\
\hline 20 & Nanning & 1 & 1 & 1 & 0.87547 & 1 & 1 & 1 & 1 \\
\hline 21 & Shanghai & 1 & 1 & 1 & 1 & 1 & 1 & 1 & 1 \\
\hline 22 & Shenyang & 0.66545 & 0.627728 & 0.63962 & 1 & 1 & 1 & 0.48321 & 1 \\
\hline 23 & Shijiazhuang & 0.50009 & 0.3922 & 0.59981 & 0.38869 & 0.82022 & 1 & 0.39356 & 0.487675 \\
\hline 24 & Taiyuan & 0.19052 & 0.163025 & 0.16824 & 0.20609 & 0.96204 & 0.41809 & 0.40877 & 0.41523 \\
\hline 25 & Tianjin & 0.69272 & 0.703578 & 0.70019 & 0.67872 & 0.93238 & 1 & 0.5781 & 0.655972 \\
\hline 26 & Wuhan & 1 & 0.749974 & 0.7602 & 0.74618 & 1 & 1 & 0.62439 & 0.497028 \\
\hline 27 & Urumqi & 1 & 1 & 0.67283 & 1 & 1 & 1 & 0.33052 & 1 \\
\hline 28 & Xian ${ }^{1}$ & 0.77568 & 0.812061 & 0.76402 & 0.73304 & 0.74055 & 1 & 0.43468 & 0.654921 \\
\hline 29 & Xining & 0.26656 & 0.233276 & 0.24415 & 0.56395 & 0.74043 & 0.49459 & 0.50091 & 0.480425 \\
\hline 30 & Yinchuan & 0.33957 & 0.369273 & 0.27203 & 0.2703 & 0.74327 & 0.57298 & 0.41242 & 0.438677 \\
\hline 31 & Zhengzhou & 0.95579 & 0.950753 & 0.96513 & 0.84935 & 0.87642 & 1 & 0.49866 & 0.749967 \\
\hline
\end{tabular}

\subsection{Comparison of Undesirable Output Efficiency and Main Policy}

From Table 8, Chengdu, Hangzhou, Hefei, Huhehot, Jinan, Lanzhou, Nanchang, Nanjing, Shenyang, Shijiazhuang, Urumqi, Yinchuan should address on the emission control of carbon dioxide and air pollutants. These cities can adjust the industrial structure and develop tertiary industries and new energy, and reduce emissions of air pollutants through the control of pollution sources such as vehicle and living air pollutants emissions.

Beijing, Changchun, Wuhan, Xian, Xining, Zhengzhou should strengthen the control of air pollutant emissions, especially on carbon dioxide emissions. The measures on industrial restructuring, industrial transformation, and energy transformation should be taken. These cities should also develop public transport, reduce air pollution emissions and use new energy and clean fossil energy to reduce the damage caused by air pollution to population health.

Changsha, Chongqing, Guiyang, Harbin, Kunming, Nanning, Taiyuan, Tianjin should focus on the management and control of carbon dioxide emissions. The above cities have better meteorological conditions, and the efficiency of air pollutants is slightly better than that of carbon dioxide emission. Therefore, in policy measures, carbon dioxide emission reduction should be priority. In particular, cities such as Taiyuan and Tianjin can achieve carbon reduction targets through industrial transformation and new energy and the reform on traditional energy use. In the meanwhile, other air pollutants emission should be reduced.

Respiratory disease efficiency and mortality efficiency are improved in most cities. Beijing, Changchun, Guiyang, Harbin, Kunming, Shenyang Shijiazhuang, Tianjin should focus on respiratory diseases and mortality and population health. Fuzhou, Guangzhou, Haikou, Lhasa, Shanghai should maintain the existing environmental efficiency and be a model. 
Table 8. Comparison of undesirable output efficiency and policy priorities of each city.

\begin{tabular}{|c|c|c|c|}
\hline DMU & Respiratory Disease and Mortality Efficiency Score & CO and AQI Efficiency Score & Main Policy \\
\hline Beijing & $\begin{array}{l}\text { Respiratory disease efficiency and mortality efficiency continue } \\
\text { to decline }\end{array}$ & $\begin{array}{l}\text { The efficiency score of } \mathrm{CO}_{2} \text { is slightly up and down, and the } \\
\text { minimum is about } 0.99 \text {. The room for improvement is very small. } \\
\mathrm{AQI} \text { is } 1 \text { in the first three years, but it declines slightly in the last } \\
\text { year. AQI efficiency is slightly lower than } \mathrm{CO}_{2} \text { in the last year. }\end{array}$ & $\begin{array}{l}\text { There is small room for improvement in efficiency of carbon emissions and air } \\
\text { pollution. Air pollution is more concerned in Beijing. }\end{array}$ \\
\hline Changchun & $\begin{array}{l}\text { Respiratory disease efficiency and mortality efficiency decline } \\
\text { slightly }\end{array}$ & $\begin{array}{l}\mathrm{CO}_{2} \text { efficiency score decreases, and drops to around } 0.81 \text { in the last } \\
\text { year. The AQI efficiency score drops from } 1 \text { in the previous two } \\
\text { years to } 0.51 \text { in } 2015 \text {. Then rises to } 0.79 \text {, the room for improvement } \\
\text { in the last two years is greater than } \mathrm{CO}_{2} \text {. }\end{array}$ & Air pollution treatment should be more important than carbon emissions. \\
\hline Changsha & $\begin{array}{l}\text { Respiratory disease efficiency and mortality efficiency have } \\
\text { risen dramatically. }\end{array}$ & $\begin{array}{l}\text { Carbon dioxide efficiency has not changed much, staying around } \\
0.66 \text {. AQI efficiency score is better than CO2, only the efficiency } \\
\text { score in } 2015 \text { is about } 0.67 \text {, and other years are } 1 .\end{array}$ & Carbon emission treatment should be prior to air pollutants. \\
\hline Chengdu & $\begin{array}{l}\text { The increase in respiratory disease efficiency and mortality } \\
\text { efficiency is small. }\end{array}$ & $\begin{array}{l}\text { The efficiency score of carbon dioxide increases slightly, around } \\
0.75 \text {. The AQI efficiency score drops from } 1 \text { in the previous two } \\
\text { years to } 0.72 \text { in } 2015 \text { and } 0.86 \text { in } 2016 \text {. AQI efficiency score is } \\
\text { slightly better than } \mathrm{CO}_{2} \text {. }\end{array}$ & Should pay attention to carbon dioxide emissions and air pollutant emissions \\
\hline Chongqing & $\begin{array}{l}\text { Respiratory disease efficiency and mortality efficiency have } \\
\text { risen, room for improvement is shrinking, and room for } \\
\text { improvement in mortality efficiency is shrinking more. }\end{array}$ & $\begin{array}{l}\text { The efficiency score of } \mathrm{CO}_{2} \text { increases slightly, around } 0.75 \text {. } \\
\mathrm{AQI} \text { efficiency score is } 1 \text { and the room for improvement is } 0 \text {. }\end{array}$ & Priority carbon dioxide emission control \\
\hline Fuzhou & $\begin{array}{l}\text { The room for improvement is } 0 \text {, indicating that these two } \\
\text { indicators are more efficient than other cities. }\end{array}$ & The room for improvement of both indicators is 0 . & \\
\hline Guangzhou & $\begin{array}{l}\text { The room for improvement is } 0 \text {, indicating that these two } \\
\text { indicators are more efficient than other cities. }\end{array}$ & The room for improvement of both indicators is 0 . & \\
\hline Guiyang & $\begin{array}{l}\text { Respiratory disease efficiency and mortality efficiency do not } \\
\text { change much, indicating that the improvement is not obvious. }\end{array}$ & $\begin{array}{l}\text { The efficiency score of } \mathrm{CO}_{2} \text { is rising but the room for improvement } \\
\text { is large. In } 2016 \text {, the efficiency score is only about } 0.61 \text {. } \\
\text { AQI efficiency score is better than } \mathrm{CO}_{2} \text {, only the efficiency score in } \\
2015 \text { is } 0.65 \text {, and other years are } 1\end{array}$ & Emissions management of carbon dioxide should be prior to air pollutants. \\
\hline Harbin & $\begin{array}{l}\text { Fluctuation in the efficiency of respiratory disease efficiency } \\
\text { and mortality efficiency, declines in } 2014 \text { and 2015, but returns } \\
\text { to } 2013 \text { levels in } 2016\end{array}$ & $\begin{array}{l}\mathrm{CO}_{2} \text { efficiency score decreases, and it is } 0.73 \text { in 2016. The } \mathrm{AQI} \\
\text { efficiency score fluctuate greatly, but it has reached } 1 . \text { in } 2016 \text {. } \\
\text { The situation is better than } \mathrm{CO}_{2} \text {. }\end{array}$ & Emissions management of carbon dioxide should be prior to air pollutants. \\
\hline Haikou & $\begin{array}{l}\text { The room for improvement is } 0 \text {, indicating that these two } \\
\text { indicators are more efficient than other cities. }\end{array}$ & The room for improvement of both indicators is 0 . & \\
\hline Hangzhou & $\begin{array}{l}\text { Mortality efficiency improves significantly, and the room for } \\
\text { improvement is reduced; respiratory disease improvement is } \\
\text { not obvious, only a small increase. }\end{array}$ & $\begin{array}{l}\text { The efficiency score of carbon dioxide fluctuates, but the efficiency } \\
\text { score is } 0.8 \text { in 2016; AQI is } 1 \text { in the previous two years, but the } \\
\text { decline in the last two years is larger, and the efficiency score in } \\
2016 \text { is } 0.72 \text {. }\end{array}$ & $\begin{array}{l}\text { Focus on carbon emissions and air pollution control. The efficiency of carbon } \\
\text { emission improvement is not obvious, the room for improvement of air } \\
\text { pollution is declining, and treatment should be strengthened }\end{array}$ \\
\hline Hefei & Both efficiency scores fluctuate and rise to 1. & $\begin{array}{l}\mathrm{CO}_{2} \text { efficiency rises to } 1 \text { in 2016; AQI efficiency score increases, } \\
\text { reaching } 1 \text { in } 2016\end{array}$ & Should pay attention to the management of carbon emissions and air pollution \\
\hline Huhehot & $\begin{array}{l}\text { Respiratory disease efficiency and mortality efficiency increase, } \\
\text { but not much. }\end{array}$ & $\begin{array}{l}\text { The } \mathrm{CO}_{2} \text { efficiency is maintained at around } 0.7 \text {, and there is room } \\
\text { for improvement; } \mathrm{AQI} \text { has some fluctuations, only } 0.4 \text { in } 2015 \text {, } \\
\text { but reached } 1 \text { in } 2016 \text {. }\end{array}$ & $\begin{array}{l}\text { Focus on carbon emissions and air pollution control. The efficiency } \\
\text { improvement of carbon emissions is not obvious, and the efficiency of air } \\
\text { pollution is not stable and should be paid attention to }\end{array}$ \\
\hline
\end{tabular}


Table 8. Cont

\begin{tabular}{|c|c|c|c|}
\hline DMU & Respiratory Disease and Mortality Efficiency Score & $\mathrm{CO}$ and $\mathrm{AQI}$ Efficiency Score & Main Policy \\
\hline Jinan & $\begin{array}{l}\text { Both indicators have risen to } 1 \text { in } 2016 \text { and the room for } \\
\text { improvement is } 0 \text {. }\end{array}$ & $\begin{array}{l}\text { The efficiency score of } \mathrm{CO}_{2} \text { reaches } 1 \text { in the last year, but it is only } \\
\text { about } 0.56 \text { in the first three years; AQI is only about } 0.48 \text { in } 2015, \\
\text { and it has reached } 1 \text { in } 2016 .\end{array}$ & Strengthen the treatment of $\mathrm{CO} 2$ emissions and air pollutant emissions \\
\hline Kunming & $\begin{array}{l}\text { The efficiency of respiratory diseases continues to decline, } \\
\text { the efficiency score of mortality has fluctuated, and the } \\
\text { mortality rate reached the highest in } 2013 \text {. }\end{array}$ & $\begin{array}{l}\text { The AQI efficiency score is significantly better than the efficiency } \\
\text { score of carbon dioxide emissions. }\end{array}$ & $\begin{array}{l}\text { Prioritize the control of } \mathrm{CO} 2 \text { emissions, but do not overlook the monitoring of } \\
\text { air pollutant emissions. }\end{array}$ \\
\hline Lanzhou & $\begin{array}{l}\text { Respiratory disease and mortality efficiency have declined } \\
\text { from the previous two years, but rose to above } 0.9 \text { in } 2016 \text {. }\end{array}$ & $\begin{array}{l}\text { The carbon dioxide emission efficiency score is lower than the AQI } \\
\text { efficiency score for four years. There is room for improvement; } \\
\text { AQI efficiency has dropped even more. }\end{array}$ & Focus on $\mathrm{CO} 2$ emissions and $\mathrm{AQI}$ \\
\hline Lhasa & $\begin{array}{l}\text { The room for improvement is } 0 \text {, indicating that these two } \\
\text { indicators are more efficient than other cities. }\end{array}$ & The room for improvement of both indicators is 0 . & \\
\hline Nanchang & The efficiency scores of the two indicators rises slightly. & $\begin{array}{l}\text { The efficiency score of } \mathrm{CO}_{2} \text { decreases slightly, and the AQI } \\
\text { efficiency score decreases from } 1 \text { in the previous two years to } \\
\text { around } 0.62 \text { in } 2015 \text { and rises to around } 0.83 \text { in } 2016 \text {. }\end{array}$ & Focus on $\mathrm{CO} 2$ emissions and $\mathrm{AQI}$ \\
\hline Nanjing & $\begin{array}{l}\text { Respiratory disease efficiency increases slightly, mortality } \\
\text { efficiency is greatly increased and the room for improvement is } \\
\text { shrinking. }\end{array}$ & $\begin{array}{l}\text { The } \mathrm{CO}_{2} \text { efficiency score increases, and it is around } 0.86 \text { in } 2016 . \\
\text { The AQI efficiency score rises first and then falls, and it is only } \\
\text { about } 0.78 \text { in } 2016 \text {. }\end{array}$ & Focus on $\mathrm{CO} 2$ emissions and $\mathrm{AQI}$ \\
\hline Nanning & $\begin{array}{l}\text { The room for improvement in the efficiency of respiratory } \\
\text { diseases is zero, and the room for improvement in mortality } \\
\text { has been zero for the first three years, with a slight decline in } \\
\text { the last year. }\end{array}$ & $\begin{array}{l}\mathrm{AQI} \text { efficiency improvement room is } 0 \text {, but } \mathrm{CO}_{2} \text { efficiency is } 1 \text { in } \\
\text { three years, but falls to } 0.88 \text { in the last year. }\end{array}$ & $\begin{array}{l}\text { Carbon dioxide emission control is prior and maintain control over air } \\
\text { pollution emissions. }\end{array}$ \\
\hline Shanghai & $\begin{array}{l}\text { The room for improvement is } 0 \text {, indicating that these two } \\
\text { indicators are more efficient than other cities. }\end{array}$ & The room for improvement of both indicators is 0 . & \\
\hline Shenyang & $\begin{array}{l}\text { Both indicators are slightly reduced, and the room for } \\
\text { improvement is slightly expanded. }\end{array}$ & $\begin{array}{l}\text { The emission efficiency of carbon dioxide has improved } \\
\text { significantly, reaching } 1 \text { in } 2016 \text {; AQI is only low in 2015, only 0.4, } \\
\text { and the other three years are } 1 \text {. }\end{array}$ & Focus on the control of carbon dioxide emissions and air pollution emissions \\
\hline Shijiazhuang & $\begin{array}{l}\text { Both indicators have declined, and the room for improvement } \\
\text { has expanded slightly. }\end{array}$ & $\begin{array}{l}\text { The } \mathrm{CO}_{2} \text { efficiency score continues to decline, only about } 0.39 \text { in } \\
2016 \text {. } \\
\text { There is still room for improvement; } \mathrm{AQI} \text { has also experiences a } \\
\text { significant and sustained decline. By } 2016 \text {, it is only about } 0.42 \text {, } \\
\text { and there is also room for improvement. }\end{array}$ & $\begin{array}{l}\text { Strengthen the management of } \mathrm{CO} 2 \text { and air pollutant emissions, take } \\
\text { comprehensive measures to reduce carbon emissions, and control pollutant } \\
\text { emissions; }\end{array}$ \\
\hline Taiyuan & Two efficiency scores rise slightly. & $\begin{array}{l}\text { The carbon dioxide efficiency score has been below } 0.2 \text {, and the } \\
\text { efficiency of AQI has decreased. In 2016, it is only about } 0.41 \text {. }\end{array}$ & $\begin{array}{l}\text { Focus on the treatment of carbon dioxide emissions, but the emissions of air } \\
\text { pollutants are also serious }\end{array}$ \\
\hline Tianjin & Both efficiency drops. & $\begin{array}{l}\text { The efficiency score of } \mathrm{CO}_{2} \text { has not changed much, and it stays } \\
\text { around } 0.7 \text {, and it is only } 0.67 \text { in 2016; AQI declines, and it is only } \\
0.66 \text { in } 2016 \text {. }\end{array}$ & $\begin{array}{l}\text { Strengthen the management of carbon dioxide emissions and emissions of air } \\
\text { pollution }\end{array}$ \\
\hline Wuhan & $\begin{array}{l}\text { Both indicators have fallen from } 1 \text { in } 2013 \text { and then increases } \\
\text { slightly, but there is still room for improvement. }\end{array}$ & $\begin{array}{l}\text { The efficiency score of } \mathrm{CO}_{2} \text { decreases, and it is only about } 0.74 \mathrm{in} \\
2016 \text {, AQI efficiency score drops, and it is only around } 0.5 \text { in } 2016 \text {. }\end{array}$ & Air pollution emission is prior to control $\mathrm{CO} 2$ emissions. \\
\hline
\end{tabular}


Table 8. Cont

\begin{tabular}{|c|c|c|c|}
\hline DMU & Respiratory Disease and Mortality Efficiency Score & CO and AQI Efficiency Score & Main Policy \\
\hline Urumqi & $\begin{array}{l}\text { Respiratory efficiency and mortality efficiency have only room } \\
\text { for improvement in 2015, and the room for improvement of } \\
\text { other years is } 0 \text {. }\end{array}$ & $\begin{array}{l}\text { Both the } \mathrm{CO}_{2} \text { efficiency score and the AQI efficiency score declines } \\
\text { in 2015, } 1 \text { in other years, but AQI is only } 0.33 \text { in } 2015 \text {. }\end{array}$ & Focus on carbon dioxide emissions and emissions of air pollutants \\
\hline Xian & Both indicators have risen slightly & $\begin{array}{l}\text { The change in carbon dioxide emissions is not obvious, and it } \\
\text { remains at around } 0.75 \text {; } \\
\text { AQI is fluctuating, only about } 0.65 \text { in } 2016 \text {. }\end{array}$ & $\begin{array}{l}\text { Air pollutant emissions treatment first but should be integrated with carbon } \\
\text { dioxide emissions. }\end{array}$ \\
\hline Xining & $\begin{array}{l}\text { Both indicators have risen, but the score for the last year of } \\
\text { respiratory disease efficiency is comparable to } 2013 \text {. } \\
\text { The mortality efficiency has increased greatly. }\end{array}$ & $\begin{array}{l}\text { The carbon dioxide efficiency score increases and reaches the } \\
\text { highest level in } 2016 \text {, but only about } 0.56 \text {, AQI fluctuates and falls } \\
\text { to around } 0.48 \text { in } 2016 \text {. }\end{array}$ & $\begin{array}{l}\text { Air pollutant emissions treatment first but should be integrated with carbon } \\
\text { dioxide emissions. }\end{array}$ \\
\hline Yinchuan & $\begin{array}{l}\text { The efficiency of respiratory diseases increases slightly, while } \\
\text { the mortality rate decreases slightly, and the mortality } \\
\text { efficiency score is close to } 1 \text {. }\end{array}$ & $\begin{array}{l}\text { Carbon dioxide is falling, and the highest efficiency score is only } \\
\text { about } 0.37 \text {. } \\
\text { By 2016, only } 0.27 \text {. AQI efficiency score is slightly higher than } \mathrm{CO}_{2} \text {, } \\
\text { but declines. By 2016, it is only about } 0.44 \text {, and there is still room } \\
\text { for improvement. }\end{array}$ & $\begin{array}{l}\text { Air pollutant emissions treatment first but should be integrated with carbon } \\
\text { dioxide emissions. }\end{array}$ \\
\hline Zhengzhou & $\begin{array}{l}\text { Respiratory efficiency decreases to } 0.61 \text { in } 2016 \text { and mortality } \\
\text { efficiency score increases. }\end{array}$ & $\begin{array}{l}\mathrm{CO}_{2} \text { efficiency scores are better than } \mathrm{AQI} \text {, but decline; } \mathrm{AQI} \text { has } \\
\text { fluctuated, and only } 0.75 \text { in } 2016\end{array}$ & $\begin{array}{l}\text { Air pollutant emissions treatment first but should be integrated with carbon } \\
\text { dioxide emissions. }\end{array}$ \\
\hline
\end{tabular}




\section{Conclusions and Policy Recommendation}

This research used a two-stage network model and undesirable output to assess the urban environmental efficiencies and health efficiencies in 31 Chinese cities from 2013 to 2016, the results from which were as follows:

(1) Of the 31 cities, only Lhasa, Guangzhou, and Shanghai had overall efficiency scores of 1 for all four years. Nanning's total efficiency score was 1 from 2013 to 2015 but fluctuated down in 2016. The overall efficiency in Beijing was 1 in 2013 and 2015, 0.94 in 2014, and 0.84 in 2016, indicating that the need for improvements in Beijing was expanding, which was also true for most other cities.

(2) Compared with the number of cities with increasing overall efficiency scores, most cities had decreasing overall efficiency scores; therefore, the improvements in overall efficiencies were not optimistic.

(3) Health expenditure efficiency in most cities was rising except for the input efficiencies in Beijing, Wuhan, Xining, and Nanning, all of which dropped significantly.

(4) Except for the cities that had GDP efficiencies of 1, there were less cities with rising GDP efficiencies (6) than cities with decreasing GDP efficiencies (11); therefore, the need for GDP efficiency improvements was expanding.

(5) The birth rate efficiency scores in Fuzhou, Guangzhou, Haikou, Lhasa, Nanning, and Shanghai were all 1, 7 cities had downward trends while the other 28 cities had upward trends; therefore, in general, this indicator was improving in most cities.

(6) The respiratory diseases treatment efficiencies decreased in 10 cities; however, in all other cities it was rising, and the need for improvements was significantly reducing.

(7) Five cities had mortality rate efficiencies of 1 and the efficiency increased significantly in 15 other cities; however, the mortality rate efficiencies declined in 11 cities.

(8) The carbon emissions efficiencies rose in most cities.

The results indicate that there was still a significant need for improvement in most cities. Therefore, it is necessary to strengthen investments in treatments, and more specific measures should be taken to effectively to increase urban pollution and health treatment efficiencies. Based on the above research conclusions, this study gives the following policy recommendations:

(1) Carbon dioxide emissions and air pollutants have brought great challenges to the environmental governance of central and local governments. The impact of air pollutants on human health is large and long-lasting and should be prioritized in governance work. Even the air pollutant efficiency of some cities is better than the carbon dioxide emissions, the reduction of air pollutants cannot be overlooked. Chengdu, Hangzhou, Hefei, Huhehot, Jinan, Lanzhou, Nanchang, Nanjing, Shenyang, Shijiazhuang, Urumqi, Yinchuan should be more effective in controlling carbon dioxide emissions and air pollution emissions, using industrial transformation, and energy transformation to achieve emission reduction. Beijing, Changchun, Wuhan, Xian, Xining, Zhengzhou should control air pollutants first and then consider carbon dioxide emissions reduction. Changsha, Chongqing, Guiyang, Harbin, Kunming, Nanning, Taiyuan, Tianjin, should control carbon dioxide emissions first and then consider the treatment and control of air pollutants. Fuzhou, Guangzhou, Haikou, Lhasa, Shanghai should maintain better environmental efficiency and continue to improve air pollutants and carbon dioxide emissions.

(2) Because China has a vast territory, there are very large differences in economic and social development. The economy in most regions in the east is significantly better than in the central and western regions. Therefore, the efficiency scores in most eastern cities (Beijing, Shanghai, Guangzhou) were at a higher level and there was less need for improvement. With rapid economic development being at the cost of increased energy consumption and environmental pollution, it is necessary to use comprehensive treatments and increase the sustainable development of the cities. 
As Beijing is the capital, it attracts significant government investment. However, the treatment efficiency was not high and was on a downward trend. Urban development consumes a great deal of energy that generates pollution, which had led to a significant decline in environmental efficiency; therefore, the treatments associated with respiratory diseases, air pollution, and carbon emissions should be strengthened.

(3) For inland cities, such as Chengdu and Chongqing, the efficiency scores in 2016 were significantly higher than in 2014 and 2015, indicating that the treatment effects were improving the overall environment. Compared with the coastal cities, many mid-western cities had lower efficiency scores, with many experiencing significant declines in treatment efficiencies in 2016. Therefore, while investment in many cities in 2016 increased, the effects have not yet been realized and it is still necessary to reduce excessive investment and resource waste.

(4) Environmental pollution in cities is associated with respiratory diseases, which was measured in terms of the respiratory disease treatment and mortality rate efficiencies. Environmental pollution problems should be solved from the source and treatment efficiency increased. Also, Beijing, Changchun, Guiyang, Harbin, Kunming, Shenyang Shijiazhuang, Tianjin should pay attention to respiratory diseases and mortality, fund improvements to the quality of medical equipment and reduce disease.

Author Contributions: Conceptualization, Y.L. and Y.-H.C.; Methodology, Y.L.; Software, Y.-H.C.; Validation, Y.L., Y.-H.C. and T-Y.L.; Formal Analysis, Y.L.; Investigation, Y.-H.C.; Resources, T-Y.L.; Data Curation, Y.L.; Writing-Original Draft Preparation, Y.L.; Writing-Review \& Editing, Y.L.; Visualization, T-Y.L.; Supervision, Y.-H.C.; Project Administration, Y.L.; Funding Acquisition, Y.L.

Funding: This study was supported by the National Natural Science Foundation of China (NO. 71773082); was funded by Sichuan University project (NO. 2018hhs-42).

Conflicts of Interest: The authors declare no conflict of interest.

\section{References}

1. World Meteorological Organization (WMO). WMO Statement on the State of Global Climate in 2017; WMO: Switzerland, Geneva, 2017.

2. OECD. International Energy Agency, 2017 Edition. Available online: www://iea.org/ (accessed on 14 November 2017).

3. Zhou, P.; Poh, K.L.; Ang, B.W. A non-radial DEA approach to measuring environmental performance. Eur. J. Oper. Res. 2007, 178, 1-9. [CrossRef]

4. Sueyoshi, T.; Mika, G. Should the US Clean Air Act Include $\mathrm{CO}_{2}$ Emission Control?: Examination by Data Envelopment Analysis. Energy Policy 2010, 38, 5902-5911. [CrossRef]

5. Shi, G.-M.; Bi, J.; Wang, J.-N. Chinese regional industrial energy efficiency evaluation based on a DEA model of fixing non-energy inputs. Energy Policy 2010, 38, 6172-6179. [CrossRef]

6. Choi, Y.; Zhang, N.; Zhou, P. Efficiency and abatement costs of energy-related $\mathrm{CO}_{2}$ emissions in China: A slacks-based efficiency measure. Appl. Energy 2012, 98, 198-208. [CrossRef]

7. Zhang, N.; Choi, Y. Environmental Energy Efficiency of China's Regional Economies: A non-oriented slacks-based measure analysis. Soc. Sci. J. 2013, 50, 225-234. [CrossRef]

8. Sueyoshi, T.; Mika, G. DEA environmental assessment in a time horizon: Malmquist index on fuel mix, electricity and $\mathrm{CO}_{2}$ of industrial nations. Energy Econ. 2013, 40, 370-382. [CrossRef]

9. Wu, A.-H.; Cao, Y.-Y.; Liu, B. Energy efficiency evaluation for regions in China: an application of DEA and Malmquist indices. Energy Effic. 2014, 7, 429-439. [CrossRef]

10. Chang, M.-C. Energy intensity, target level of energy intensity, and room for improvement in energy intensity: an application to the study of regions in the EU. Energy Policy 2014, 67, 648-655. [CrossRef]

11. Wang, K.; Wei, Y.-M. China's regional industrial energy efficiency and carbon emissions abatement costs. Appl. Energy 2014, 130, 617-631. [CrossRef]

12. Pang, R.-Z.; Deng, Z.-Q.; Hu, J.-L. Clean energy use and total-factor efficiencies: an international comparison. Renew. Sustain. Energy Rev. 2015, 52, 1158-1171. [CrossRef] 
13. Guo, X.; Lu, C.-C.; Lee, J.-H.; Chiu, Y.-H. Applying the dynamic DEA model to evaluate the energy efficiency of OECD countries and China Energy. Energy 2017, 134, 392-399. [CrossRef]

14. Georgiev, E.; Mihaylo, E.S. Economic growth and the environment: reassessing the environmental Kuznets Curve for air pollution emissions in OECD countries. Lett. Spat. Resour. Sci. 2015, 8, 29-47. [CrossRef]

15. He, L.-Y.; Ou, J.-J. Pollution Emissions, Environmental Policy, and Marginal Abatement Costs. Int. J. Environ. Res. Public Health 2017, 14, 1509. [CrossRef] [PubMed]

16. Li, L.; Lei, Y.; Pan, D.; Yu, C.; Si, C. Economic evaluation of the air pollution effect on public health in China's 74 cities. Springer Plus 2016, 5, 402. [CrossRef]

17. Wang, Z.-X.; Hao, P.; Yao, P.-Y. Non-Linear Relationship between Economic Growth and $\mathrm{CO}_{2}$ Emissions in China: An Empirical Study Based on Panel Smooth Transition Regression Models. Int. J. Environ. Res. Public Health 2017, 14, 1568. [CrossRef] [PubMed]

18. Xie, Y.; Dai, H.; Dong, H.; Hanaoka, T.; Masui, T. Economic impacts from PM2. 5 pollution-related health effects in China: A provincial-level analysis. Environ. Sci. Technol. 2016, 50, 4836-4843. [CrossRef] [PubMed]

19. Liu, W.; Xu, Z.; Yang, T. Health Effects of Air Pollution in China. Int. J. Environ. Res. Public Health 2018, 15, 1471. [CrossRef]

20. Zanoni, S.; Stefani, P.; Ionescu, G.; Zambelli, P. Assessing Some Criticalities of Particulate Matter Exposure in an Urban Context. WIT Trans. Ecol. Environ. 2014, 191, 1391-1402.

21. Kelly, F.J.; Fussell, J.C. Air pollution and public health: emerging hazards and improved understanding of risk. Environ. Geochem. Health 2015, 3, 631-649. [CrossRef]

22. Fischer, P.H.; Marra, M.; Ameling, C.B.; Hoek, G.; Beelen, R.; de Hoogh, K.; Breugelmans, O.; Kruize, H.; Janssen, N.A.H.; Houthuijs, D. Air pollution and mortality in seven million adults: the Dutch Environmental Longitudinal Study (DUELS). Environ. Health Persp. 2015, 123, 697. [CrossRef]

23. Khafaie, M.A.; Ojha, A.; Salvi, S.S.; Yajnik, C.S. Methodological approach in air pollution health effects studies. J. Air Pollut. Health 2016, 1, 219-226.

24. Khafaie, M.A.; Yajnik, C.S.; Salvi, S.S.; Ojha, A. Critical review of air pollution health effects with special concern on respiratory health. J. Air Pollut. Health 2016, 1, 123-136.

25. Tainio, M.; de Nazelle, A.J.; Götschi, T.; Kahlmeier, S.; Rojas-Rueda, D.; Nieuwenhuijsen, M.J.; Woodcock, J. Can air pollution negate the health benefits of cycling and walking? Prevent. Med. 2016, 87, 233-236. [CrossRef] [PubMed]

26. San, J.R.; Luis, P.J.; Libia, P.; Barras, G.; Maria, R. Effects of climate change on the health of citizens modelling urban weather and air pollution. Energy 2018, 165, 53-62.

27. Torretta, V.; Raboni, M.; Copelli, S.; Rada Elena, C.; Marco, R.; Ionescu, G.; Apostol, T.; Badea, A. Application of strategies for particulate matter reduction in urban areas: An Italian case. UPB Sci. Bull. Sér. D Mech. Eng. 2013, 75, 221-228.

28. Schiavon, M.; Redivo, M.; Antonacci, G.; Rada, E.; Cristina, R.M.; Dino, Z.; Giovannini, L. Assessing the air quality impact of nitrogen oxides and benzene from road traffic and domestic heating and the associated cancer risk in an urban area of Verona (Italy). Atmos. Environ. 2015, 120, 234-243. [CrossRef]

29. Schiavon, M.; Antonacci, G.; Rada, E.C.; Ragazzi, M.; Zardi, D. Modelling Human Exposure to Air Pollutants in an Urban Area. Rev. Chim. Buchar. Orig. Ed. 2014, 65, 61-64.

30. Cohen, A.J.; Brauer, M.; Burnett, R.; Anderson, H.R.; Frostad, J.; Estep, K.; Balakrishnan, K.; Brunekreef, B.; Dandona, L.; Dandona, R.; et al. Estimates and 25-year trends of the global burden of disease attributable to ambient air pollution: an analysis of data from the Global Burden of Diseases Study 2015. Lancet 2017, 389, 1907-1918. [CrossRef]

31. Johansson, C.; Lövenheim, B.; Schantz, P.; Wahlgren, L.; Almström, P.; Markstedt, A.; Sommar, J.N. Impacts on air pollution and health by changing commuting from car to bicycle. Sci. Total Environ. 2017, 584, 55-63. [CrossRef]

32. Newell, K.; Kartsonaki, C.; Lam, K.B.H.; Kurmi, O.P. Cardiorespiratory health effects of particulate ambient air pollution exposure in low-income and middle-income countries: a systematic review and meta-analysis. Lancet Planet. Health 2017, 1, e368-e380. [CrossRef]

33. Kinney, P.L. Interactions of Climate Change, Air Pollution, and Human Health. Curr. Environ. Health Rep. 2018, 5, 1-8. [CrossRef] 
34. Lua, X.; Lin, C.; Li, W.; Chen, Y.; Huang, Y.; Funga, J.; Lau, C.H.; Alexis, K.H. Analysis of the adverse health effects of PM2.5 from 2001 to 2017 in China and the role of urbanization in aggravating the health burden. Sci. Total Environ. 2019, 652, 683-695. [CrossRef]

35. Zigler, C.M.; Choirat, C.; Dominici, F. Impact of National Ambient Air Quality Standards nonattainment designations on particulate pollution and health. Epidemiology 2018, 29, 165-174. [CrossRef]

36. Frischer, T.; Studnicka, M.; Gartner, C.; Tauber, E.; Horak, F.; Veiter, A. Lung function growth and ambient ozone: A 3-year population study in schoolchildren. Am. J. Respir. Crit. Care Med. 1999, 160, 390-396. [CrossRef] [PubMed]

37. Ye, F.; Piver, W.; Ando, M.; Portier, C. Effects of temperature and air pollutants on cardiovascular and respiratory diseases for males and females older than 65 years of age in Toyko, July and August 1980-1995. Environ. Health Perspect. 2001, 109, 355-359. [CrossRef] [PubMed]

38. Lee, J.; Kim, H.; Song, H.; Hong, Y.; Cho, Y.; Shin, S. Air pollution and asthma among children in Seoul, South Korea. Epidemiology 2002, 13, 481-484. [CrossRef]

39. Gauderman, W.J.; Gilliland, G.F.; Vora, H.; Avol, E.; Stram, D.; McConnell, R. Association between air pollution and lung function growth in southern California schoolchildren: results from a second cohort. Am. J. Respir. Crit. Care Med. 2002, 166, 76-84. [CrossRef] [PubMed]

40. Chen, Y.; Yang, Q.; Krewski, D.; Shi, Y.; Burnett, R.T.; McFrail, K. Influence of relatively low level particulate air pollution and hospitalization for COPD in elderly people. Inhal. Toxicol. 2004, 16, 21-25. [CrossRef]

41. Penard-Morand, C.; Charpin, D.; Raherison, C.; Kopferschmitt, C.; Callaud, D.; Lavaud, F. Long-term exposure to background air pollution related to respiratory and allergic health in schoolchildren. Clin. Exp. Allergy 2005, 35, 1279-1287. [CrossRef]

42. Barnett, A.G.; Williams, G.M.; Schwartz, J.; Neller, A.H.; Best, T.L.; Petroeschevsky, A.L. Air pollution and child respiratory health: A case-crossover study in Australia and New Zealand. Am. J. Respir. Crit. Care Med. 2005, 171, 1272-1278. [CrossRef]

43. Choe, S.A.; Jun, Y.B.; Lee, W.S. Association between ambient air pollution and pregnancy rate in women who underwent IVF. Hum Reprod. 2018, 33, 5-12. [CrossRef] [PubMed]

44. Wang, Y.; Shi, L. Long-term Exposure to PM2.5 and Mortality Among Older Adults in the Southeastern US. Epidemiology 2017, 28, 207-214. [CrossRef] [PubMed]

45. Charnes, A.; Cooper, W.; Rhodes, E. Measuring the Efficiency of Decision-Making Units. Eur. J. Oper. Res. 1978, 2, 429-444. [CrossRef]

46. Farrell, M.J. The Measurement of Productive Efficiency. J. R. Stat. Soc. 1957, 120, 253-281. [CrossRef]

47. Banker, R.D.; Charnes, R.F.; Cooper, W.W. Some Models for Estimating Technical and Scale Inefficiencies in Data Envelopment Analysis. Manag. Sci. 1984, 30, 1078-1092. [CrossRef]

48. Tone, K. A slacks-based measure of efficiency in data envelopment analysis. Eur. J. Oper. Res. 2001, 130, 498-509. [CrossRef]

49. Tone, K.; Tsutsui, M. An epsilon-based measure of efficiency in DEA-A third pole of technical efficiency. Eur. J. Oper. Res. 2010, 207, 1554-1563. [CrossRef]

50. Färe, R.; Grosskopf, S.; Pasurka, C.A. Environmental production functions and environmental directional distance functions. Energy 2007, 32, 1055-1066. [CrossRef]

51. Zhu, J. Efficiency evaluation with strong ordinal input and output measures. Eur. J. Oper. Res. 2003, 146, 477-485. [CrossRef]

52. Zhu, C.Y.; Zhu, J. Measuring Information Technology's Indirect Impact on Firm Performance. Inform. Technol. Manag. J. 2004, 5, 9-22.

53. Kang, C.-C. Analyzing for Production Efficiency in Telecommunications Industry: The Taiwan Case. Bus. Rev. Camb. 2006, 5, 111-120.

54. Kao, C.; Hwang, S.N. Efficiency Decomposition in Two-Stage Data Envelopment Analysis: An Application to Non-life Insurance Companies in Taiwan. Eur. J. Oper. Res. 2008, 185, 418-429. [CrossRef]

55. Kao, C. Efficiency measurement for parallel production systems. Eur. J. Oper. Res. 2009, 196, 1107-1112. [CrossRef]

56. Tone, K.; Tsutsui, M. Network DEA: A Slacks Based Measurement Approach. Eur. J. Oper. Res. 2009, 197, 243-252. [CrossRef]

57. Hu, J.L.; Wang, S.C. Total-factor energy efficiency of regions in China. Energy Policy 2006, 34, 3206-3217. [CrossRef] 
58. National Bureau of Statistics of China. China Statistical Yearbook; National Bureau of Statistics of China: Beijing, China, 2017.

59. China Statistical Yearbooks Database. Demographics and the Employment Statistical Yearbook of China, and the Statistical Yearbooks of all Cities; China Academic Journals Electronic Publishing House: Beijing, China, 2017.

60. China's Environmental and Protection Bureau Reports; Ministry of Ecology and Environment of the People's Republic of China: Beijing, China, 2017.

61. China National Bureau of Surveying and Mapping. Available online: http://bzdt.nasg.gov.cn/index.jsp (accessed on 1 January 2018).

(C) 2019 by the authors. Licensee MDPI, Basel, Switzerland. This article is an open access article distributed under the terms and conditions of the Creative Commons Attribution (CC BY) license (http:/ / creativecommons.org/licenses/by/4.0/). 